OPEN ACCESS

Edited by:

Jeremy Turnbull,

University of Liverpool,

United Kingdom

Reviewed by:

Shuji Mizumoto,

Meijo University, Japan

Herbert M. Geller,

National Heart, Lung, and Blood Institute (NHLBI), United States

*Correspondence:

Fuchuan Li

fuchuanli@sdu.edu.cn

Specialty section:

This article was submitted to

Signaling,

a section of the journal

Frontiers in Cell and Developmental

Biology

Received: 08 May 2020

Accepted: 05 November 2020

Published: 03 December 2020

Citation:

Wang W, Shi L, Qin Y and Li F (2020) Research and Application of Chondroitin Sulfate/Dermatan

Sulfate-Degrading Enzymes.

Front. Cell Dev. Biol. 8:560442. doi: $10.3389 /$ fcell.2020.560442

\section{Research and Application of Chondroitin Sulfate/Dermatan Sulfate-Degrading Enzymes}

\author{
Wenshuang Wang, Liran Shi, Yong Qin and Fuchuan Li* \\ National Glycoengineering Research Center and Shandong Provincial Key Laboratory of Carbohydrate Chemistry \\ and Glycobiology, Shandong University, Jinan, China
}

Chondroitin sulfate (CS) and dermatan sulfate (DS) are widely distributed on the cell surface and in the extracellular matrix in the form of proteoglycan, where they participate in various biological processes. The diverse functions of CS/DS can be mainly attributed to their high structural variability. However, their structural complexity creates a big challenge for structural and functional studies of CS/DS. CS/DS-degrading enzymes with different specific activities are irreplaceable tools that could be used to solve this problem. Depending on the site of action, CS/DS-degrading enzymes can be classified as glycosidic bond-cleaving enzymes and sulfatases from animals and microorganisms. As discussed in this review, a few of the identified enzymes, particularly those from bacteria, have wildly applied to the basic studies and applications of CS/DS, such as disaccharide composition analysis, the preparation of bioactive oligosaccharides, oligosaccharide sequencing, and potential medical application, but these do not fulfill all of the needs in terms of the structural complexity of CS/DS.

Keywords: chondroitin sulfate, dermatan sulfate, structure-function relationships, oligosaccharide, enzymes

\section{STRUCTURE AND FUNCTIONS OF CHONDROITIN SULFATE/DERMATAN SULFATE}

As a major member of the glycosaminoglycan (GAG) family, chondroitin sulfate (CS)/dermatan sulfate (DS) chains covalently attach to core proteins to form CS/DS proteoglycans (CS/DSPGs), which are widespread on cell surfaces and within extra/pericellular matrices to regulate the extracellular environment, involving in many biological and pathophysiological activities (Sugahara and Kitagawa, 2000). As the side chains of PGs, CS is composed of repeating disaccharides consisting of D-glucuronic acid (GlcA) and $N$-acetylgalactosamine (GalNAc) with different sulfation patterns, once the GlcA residues are isomerized to L-iduronic acid (IdoA) residues CS is converted to DS, also called CS-B, and CS and DS domains are usually detected in one chain as co-hybrid structure CS/DS (Sugahara et al., 2003; Figure 1). The sulfated modification of CS/DS chains at C-4 and/or C-6 of GalNAc or/and C-2 of GlcUA/IdoUA by various specific sulfotransferases generates significant structural diversity (Kusche-Gullberg and Kjellen, 2003; Figure 1). Monosulfated disaccharide GlcA $\beta 1-3 \mathrm{GalNAc}(4 \mathrm{~S})$ (A unit) and GlcA $\beta 1-3 \mathrm{GalNAc}(6 \mathrm{~S})$ (C unit), of which $4 \mathrm{~S}$ and $6 \mathrm{~S}$ stand for 4-O-sulfate and 6-O-sulfate, respectively, are the most common components found in CS from terrestrial animals (Mathews, 1958; Table 1). Additionally, some highly sulfated disaccharides, such as GlcA(2S) $\beta 1-3 \mathrm{GalNAc}(6 \mathrm{~S})$ (D unit), of which $2 \mathrm{~S}$ stands for 2-O-sulfate, and GlcAß1-3GalNAc(4S, 6S) (E unit), have been found in CS/DS from mammals, 
in which they account a relatively low proportion but play very important roles in various functions of CS/DS chains (Nandini and Sugahara, 2006; Table 1). In contrast, DS from mammals is mainly composed of the iA unit (IdoA $\alpha 1-3 \mathrm{GalNAc}(4 \mathrm{~S})$ ) with a small amount of the iB unit (IdoA(2S) $\alpha 1-3 \mathrm{GalNAc}(4 \mathrm{~S})$ ) (Bao et al., 2005; Nandini and Sugahara, 2006). Interestingly, some CS/DS chains from marine animals contain a high proportion of rare highly sulfated disaccharides, such as the $\mathrm{D}$ unit in CS from shark fin and the E unit in CS from squid cartilage (Mizumoto et al., 2013a; Ueoka et al., 2000; Table 1). Traditionally, CS/DS is named based the main common disaccharide unit or enriched rare disaccharide unit, such as CSA from mammalian cartilage and sturgeon notochord containing A unit as main disaccharide, CS-C from shark cartilage containing $\mathrm{C}$ unit as main disaccharide, CS-D from shark fin containing rare D unit, and CS-E from squid cartilage containing rare $\mathrm{E}$ unit. CS/DS chains are widely present in connective tissues of vertebrates and invertebrates, and the polymerization degree and sulfation pattern of CS/DS polysaccharide chains determine the physicochemical properties and physiological and pharmacological activities of CS/DS and CS/DSPGs. The structure complexity of CS/DS leads to its functional diversity. More and more studies have shown that CS/DS is involved in cell division and differentiation (Sugahara et al., 2003; Mizuguchi et al., 2003; Bülow and Hobert, 2006; Izumikawa et al., 2010; Schwartz and Domowicz, 2018; Shida et al., 2019), cell adhesion (Sugahara et al., 2003; Handel et al., 2005; Bülow and Hobert, 2006; Sugahara and Mikami, 2007), morphogenesis (Klüppel et al., 2005; Hayes et al., 2018), inflammation (Li et al., 2020; Campo et al., 2009) and viral infection (Hsiao et al., 1999; Bergefall et al., 2005; Kim et al., 2017). CS/DS chains carry out these functions through interacting with target proteins such as various growth factors fibroblast growth factor (FGF), hepatocyte growth factor (HGF) and pleiotrophin (PTN) (Nandi et al., 2006; Taylor and Gallo, 2006) and cytokines (Hwang et al., 2003; Mizuguchi et al., 2003; Izumikawa et al., 2004; Mizumoto and Sugahara, 2013).

\section{CS/DS BIOSYNTHESIS}

The biosynthesis of CS/DS is a complex, multistep and enzymatically accommodated process that occurs in endoplasmic reticulum/Golgi compartments and is initiated by the synthesis of GAG-protein linkage region covalently linked to specific serine residues embedded in different core proteins (Sugahara and Kitagawa, 2000; Silbert and Sugumaran, 2002; Sugahara et al., 2003). The linkage region is a specific tetrasaccharide structure GlcA $\beta 1-3 \mathrm{Gal} \beta 1-3 \mathrm{Gal} \beta 1-4 \mathrm{Xyl} \beta 1$, in which Gal and Xyl represent galactose and xylose residues, respectively (Figure 1). This structure is catalyzed by the corresponding glycosyltransferase in the tetrasaccharide sequence. Firstly, a Xyl residue is connected to a specific Ser residue of core protein through the catalyzation of xylosyltransferase (Götting et al., 2000, 2007); then, $\beta 1,4$ galactosyltransferase I (Almeida et al., 1999; Okajima et al., 1999) and $\beta 1,3$-galactosyltransferase II (Bai et al., 2001) catalyze the connection of two Gal residues in turn; and, finally, $\beta 1,3$ glucuronyltransferase I (Kitagawa et al., 1998; Bai et al., 1999,
2001) catalyzes the addition of GlcUA residue to form the tetrasaccharide linkage region.

Once the synthesis of the linkage tetrasaccharide is completed, the extension of CS/DS chain will be triggered by the transfer of a GalNAc residue to the nonreducing terminal GlcA residue of the tetrasaccharide linkage region by GalNAc transferase I, and then GlcA and GalNAc residues will be added in turn to form the chondroitin (Chn) skeleton composed of repeating disaccharide GlcA-GlaNAc through alternating catalysis of GalNAc transferase II and GlcA transferase II (Sugahara and Kitagawa, 2000; Silbert and Sugumaran, 2002; Sugahara et al., 2003). During the process of polymerization, some GlcA residues in the Chn skeleton can be transformed into IdoA under the control of two GlcA C-5 epimerases, thereby transforming the corresponding Chn domains into its stereoisomer dermatan domains (Maccarana et al., 2006; Pacheco et al., 2009). Furthermore, some hydroxyl groups of GalNAc or GlcA/IdoA residues in the chains can be site-specifically modified by a variety of sulfotransferases by using 3'-phosphoadenosine 5'-phosphosulfate as a donor substrate (Habuchi, 2000). Under the control of chondroitin 4O-sulfotransferase-1, 2 and 3 (Yamauchi et al., 2000; Hiraoka et al., 2000; Kang et al., 2002), and dermatan 4-O-sulfotransferase (Evers et al., 2001; Mikami et al., 2003) the sulfate group is transferred to the hydroxyl group at the C-4 location of GlcA to generate an $\mathrm{A}$ unit and an iA unit, respectively. The 6-O-sulfation of the $\mathrm{C}$ unit is catalyzed by chondroitin 6-O-sulfotransferase-1 (Fukuta et al., 1998). The GalNAc 4-sulfate 6-O-sulfotransferase transfers sulfate to the $\mathrm{C}-6$ position of the A/iA unit to generate an E/iE unit (Ohtake et al., 2001), and uronyl 2-O-sulfotransferase sulfates GlcA in the C-2 position of the C/iA unit to generate a D/iB unit (Kobayashi et al., 1999). The space-time-dependent expression and combined action of these enzymes make the structure of CS/DS chains extremely diverse and complex, which presents significant challenges for the structural and functional studies of CS/DS.

\section{CS/DS-DEGRADING ENZYMES}

As a reverse process of CS/DS synthesis, the degradation of CS/DS chains in the organisms also involves various enzymes including glycosidic bond-cleaving enzymes and sulfatases, which correspond to glycosyltransferases and sulfotransferases, respectively. Thus, the CS/DS-degrading enzymes are indispensable tools for analyzing the structure and function of CS/DS chains. Based on the enzymatic mechanism, CS/DS glycosidic bond-cleaving enzymes are accordingly classified as either hydrolases or lyases. According to their similarities of amino acid sequences, hydrolases and lyases are assigned to glycoside hydrolase $(\mathrm{GH})$ families and polysaccharide lyase (PL) families, respectively (Henrissat, 1991). CS/DS hydrolases and lyases are usually found in animals and microorganisms, respectively. CS/DS sulfatases belong to the formylglycine-dependent family that specifically hydrolyzes sulfate esters on poly- and oligosaccharides of CS/DS. These CS/DS-degrading enzymes play key roles in the catabolic metabolism of CS/DS polysaccharides and are widely found in animals and microorganisms. 


\section{Hydrolases}

In animals, CS/DS glycosidic bond-cleaving enzymes are hydrolases that cleave the $\beta$-1,4-glycosidic bond between GalNAc and GlcA residues in CS chains via a hydrolysis mechanism to produce saturated oligosaccharide products (Kreil, 1995). In mammals, the so-called hyaluronidases (EC 3.2.1.35) have been reported to be the only hydrolases that cleave CS chains, and even some hyaluronidases do not degrade hyaluronan (HA) but only degrade CS (Kaneiwa et al., 2010). In fact, most animal-derived hyaluronidases and microorganism-derived CS/DS lyases, which we will introduce later, show both HAand Chn/CS-degrading activities, which may be due to the very similar structural features of the two GAG polysaccharides. Both $\mathrm{HA}$ and CS chains have same types of $\beta$-glycosidic bonds in

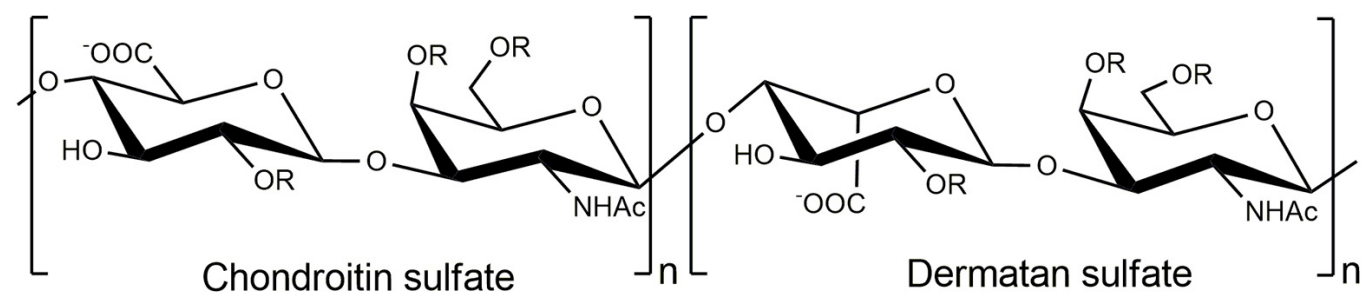

$\mathrm{R}=\mathrm{H}$ or $\mathrm{SO}_{3}^{-}$

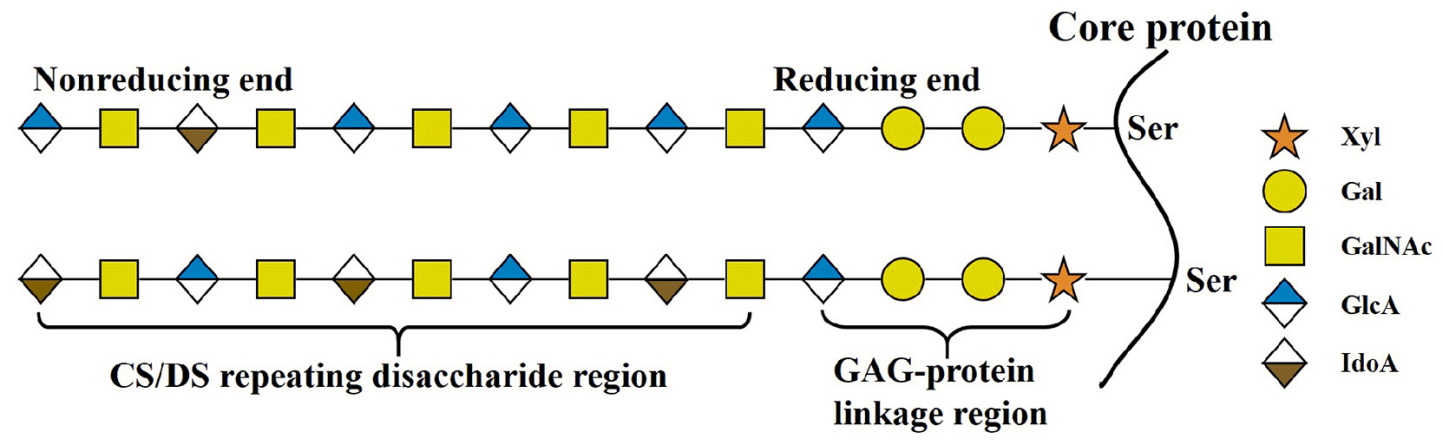

FIGURE 1 | The structure of CS/DS. The CS/DS chain consisting of D-glucuronic acid (GlcA) or L-iduronic (IdoA) acid glycosidically linked to N-acetylgalacyosamine (GalNAc) [(-4GlcA 1 1-3GalNAc $\beta 1$-) or (-4IdoA $\alpha 1-3 \mathrm{GalNAc} \beta 1-)$. CS/DS chains are covalently attached to the core protein by GAG-protein linkage region tetrasaccharide.

TABLE 1 | The CS/DS disaccharide and unsaturated disaccharide produced by CS/DS lyase.

\begin{tabular}{|c|c|c|c|c|c|}
\hline \multicolumn{2}{|r|}{ CS units } & \multicolumn{2}{|r|}{ DS units } & \multicolumn{2}{|r|}{ Unsaturated units } \\
\hline Unit & Sequence & Unit & Sequence & Unit & Sequence \\
\hline O unit & GlcA $\beta 1-3 G a l N A c$ & iO unit & IdoA $\alpha 1-3 G a \mid N A c$ & $\Delta \mathrm{O}$ unit & $\Delta$ HexA-GalNAc \\
\hline A unit & GlcA $\beta 1-3 G a l N A c(4 S)$ & iA unit & IdoA $\alpha 1-3 G a I N A c(4 S)$ & $\Delta \mathrm{A}$ unit & $\Delta$ HexA-GalNAc(4S) \\
\hline B unit & GlcA(2S)ß1-3GalNAc(4S) & iB unit & IdoA(2S)a1-3GalNAc(4S) & $\Delta \mathrm{B}$ unit & $\Delta \mathrm{HexA}(2 \mathrm{~S})-\mathrm{GalNAc}(4 \mathrm{~S})$ \\
\hline C unit & GlcA $\beta 1-3 G a l N A c(6 S)$ & iC unit & IdoA $\alpha 1-3 G a I N A c(6 S)$ & $\Delta \mathrm{C}$ unit & $\Delta \mathrm{HexA-GalNAc(6S)}$ \\
\hline D unit & GlcA(2S)ßק1-3GalNAc(6S) & iD unit & IdoA(2S) $\alpha 1-3 G a \mid N A c(6 S)$ & $\Delta \mathrm{D}$ unit & $\Delta \mathrm{HexA}(2 \mathrm{~S})-\mathrm{GalNAc}(6 \mathrm{~S})$ \\
\hline E unit & GlcA $\beta 1-3 G a I N A c(4 S, 6 S)$ & $\mathrm{iE}(\mathrm{H})$ unit & IdoA $\alpha 1-3 G a I N A c(4 S, 6 S)$ & $\Delta E$ unit & $\Delta$ HexA-GalNAc(4S,6S) \\
\hline F unit & $\begin{array}{l}\text { GlcA } \beta 1-3 G a l N A c(4 S) \\
\mid \\
\text { Fuc }(\alpha 1-3)\end{array}$ & iK unit & IdoA(3S) $\alpha 1-3 G a l N A c(4 S)$ & $\Delta F$ unit & $\begin{array}{l}\Delta \text { HexA-GalNAc(4S) } \\
\quad \mid \\
\text { Fuc }(\alpha 1-3)\end{array}$ \\
\hline G unit & $\begin{array}{c}\text { GlcA } \beta 1-3 \text { GalNAc(4S) } \\
\mid \\
\text { Glc }(\beta 1-6)\end{array}$ & iL unit & IdoA(3S) $\alpha 1-3 G a l N A c(6 S)$ & $\Delta \mathrm{G}$ unit & $\begin{array}{c}\Delta \text { HexA-GalNAc(4S) } \\
\mid \\
\operatorname{Glc}(\beta 1-6)\end{array}$ \\
\hline K unit & GlcA(3S)ß1-3GalNAc(4S) & iT unit & IdoA(2S) $\alpha 1-3 \mathrm{GalNAc}(4 \mathrm{~S}, 6 \mathrm{~S})$ & $\Delta K$ unit* $^{\star}$ & $\Delta \mathrm{HexA}(3 \mathrm{~S})$-GalNAc(4S) \\
\hline L unit & GlcA(3S)ß1-3GalNAc(6S) & iU unit & IdoA(2S) $\alpha 1-3 \mathrm{GalNAc}$ & $\Delta L$ unit $^{\star}$ & $\Delta \mathrm{HexA}(3 \mathrm{~S})-\mathrm{GalNAc}(6 \mathrm{~S})$ \\
\hline M unit & GlcA(3S)ß1-3GalNAc(4S,6S) & & & $\Delta M$ unit* & $\Delta \mathrm{HexA}(3 \mathrm{~S})$-GalNAc(4S,6S) \\
\hline T unit & GlcA(2S)ß1-3GalNAc(4S,6S) & & & $\Delta T$ unit & $\Delta \mathrm{HexA}(2 \mathrm{~S})-\mathrm{GalNAc}(4 \mathrm{~S}, 6 \mathrm{~S})$ \\
\hline U unit & GlcA(2S)B1-3GalNAc & & & $\Delta \mathbf{U}$ unit & $\Delta \operatorname{HexA}(2 \mathrm{~S})$-GalNAc \\
\hline
\end{tabular}

${ }^{*}$ The disaccharides containing $\triangle$ HexA (3S) are unstable and result in sulfated GalNAc. 
and between repeating disaccharide units consisting of GlcA and hexosamine residues, and the only difference in structure between them is that the acetylated hexosamine GlcNAc in $\mathrm{HA}$ is replaced by the GalNAc in the Chn skeleton of CS. In addition, like other glycoside hydrolases, hyaluronidases exhibit certain transglycosidase activities (Hoffman et al., 1956), which can be used for synthesizing of HA (Kobayashi et al., 2003), Chn (Kobayashi et al., 2003), CS (Fujikawa et al., 2005), their derivatives (Ochiai et al., 2007b; Kobayashi et al., 2003), and hybrids of HA-Chn and HA-CS (Ochiai et al., 2007a).

In human genome, six highly homologous genes have been found to encode hyaluronidase-like sequences including five functional hyaluronidases genes (HYAL1, HYAL2, HYAL3, HYAL4 and SPAM1) and a pseudogene HYALP1(also called HYAL6P) that is transcribed in humans but is not translated (Csoka et al., 2001; Stern and Jedrzejas, 2006). HYAL1, HYAL2, and HYAL3 are clustered in the chromosome 3p21.3 locus, whereas the HYAL4, SPAM1(encodes PH-20) and HYALP1 genes are found on chromosome 7q31.3 (Csoka et al., 2001; Stern, 2003). Based on the optimal $\mathrm{pH}$, most of these hyaluronidases show their highest activity at an acidic pH (Lokeshwar et al., 2001; Sabeur et al., 1997). As mentioned above, these so-called hyaluronidases from humans also show a certain degree of CSdegrading activity. The sperm-specific enzyme $\mathrm{PH}-20$ shows much higher activity against $\mathrm{Chn}$ than CSA and $\mathrm{HA}$ at $\mathrm{pH} 4.5$, whereas prefers HA and CS to Chn at pH 4.0 (Honda et al., 2012). In contrast, plasma hyaluronidase HYAL1 prefers to degrade CSA than HA at pH 4.5 but prefers HA than CS-A at pH 3.5 (Csoka et al., 2001; Honda et al., 2012; Yamada, 2015). Furthermore, C units in CS-C negatively affect the hyaluronidase activity of $\mathrm{PH}$ 20. More interestingly, HYAL4 has been shown to be a specific CS-degrading enzyme without any activity toward HA, which means that the name of hyaluronidase is a misnomer for this enzyme (Csoka et al., 2001; Stern, 2003; Jedrzejas and Stern, 2005; Kaneiwa et al., 2010). The HYAL1 and PH-20 with CS-degrading activity cannot cleave the galactosaminidic linkages in -GalNAcIdoA- and-GalNAc-GlcA(2S)- sequences, which are often found in DS chains and in highly sulfated D unit-containing domains of CS chains, respectively. In contrast, HYAL4 could strongly cleave the galactosaminidic linkages in -GlcA(2S)-GalNAc(6S)-GlcAGalNAc(4S or 6S)- (Kaneiwa et al., 2010), suggesting that HYAL4 plays an important role in the degradation of CS in mammal. However, the degradation mechanism of DS chains in animals remains to be further investigated. Enzymes HYAL1 and HYAL2 are the main HA-degrading enzymes in somatic tissues. HYAL1 is a lysosomal enzyme and by contrast HYAL2 binds to plasma membrane via a glycosylphosphatidylinositol anchor (Afify et al., 1993; Rai et al., 2001). The traditional HA degradation model is that high molecular weight HA is digested into low molecular weight HA oligosaccharides by extracellular HYAL2, then, the HA oligosaccharides are internalized by interaction with cell surface receptors, and the internalized HA oligosaccharides are further decomposed by lysosomal HYAL1, exoglycosidases $\beta$-glucuronidase and $\beta$-hexosaminidase (Hex) (Stern, 2003; Stern, 2004; Figure 2 and Table 2). As a dimeric enzyme, human Hex exists in two main isoforms $\operatorname{HexA}(\alpha \beta)$ and $\operatorname{HexB}(\beta \beta)$, of which the $\alpha$ - and $\beta$-subunits are encoded by HexA and $\operatorname{HexB}$ genes, respectively (Chiricozzi et al., 2014). Interestingly, HexA can hydrolyze HA and CS chains from their non-reducing ends but HexB cannot (Thompson et al., 1973; Bearpark and Stirling, 1978). Like HA, CS can be internalized by interaction with cell surface receptors and degraded in the lysosome (Wood et al., 1973). Indeed, mice lost both HYAL1 and Hex activity show the accumulation of HA and CS (Gushulak et al., 2012).

\section{Lyases}

Unlike the hyaluronidases from animals, CS/DS-lyases from microorganisms cleave the $\beta$-1,4-glycosidic linkage between hexosamine and hexuronic acid residues in $\mathrm{HA}$ or CS/DS chains through an elimination reaction to yield an unsaturated double bond between $\mathrm{C}-4$ and $\mathrm{C}-5$ on the uronic acid residue $\Delta^{4,5}$ hexuronate ( $\triangle \mathrm{HexA}$ ) at the nonreducing end of the resulting oligosaccharide products. Conventionally, CD/DS lyases are named as chondroitinases (CSases), although some of them cannot digest CS, such as CSase B, which shows specific activity towards DS only. Moreover, CS/DS lyases can be classified into endolytic and exolytic types according to their substrate-degrading patterns, in which endolyases cleave CS/DS chains initially into larger oligosaccharides and finally to small disaccharides with a random cleavage pattern, whereas exolyases successively release disaccharides from the end of the sugar chains and do not produce any larger oligosaccharides in the process. The unsaturated double bond of oligosaccharides produced by lyases shows specific absorption of ultraviolet light at $232 \mathrm{~nm}$, which is beneficial for the detection of CS/DS oligosaccharide products. In addition, CS/DS lyases have many advantages such as more diversity, better stability and activity and simpler preparation compared with hydrolases. Due to the outstanding features above, lyase has a wide range of applications in the preparation of oligosaccharides (Li et al., 2007; Mizumoto et al., 2013a), treatment of nerve damage (Janzadeh et al., 2017; Mondello et al., 2015; Sarveazad et al., 2017), and other CS structure-activity relationship studies.

\section{Commercialized CS/DS Lyases}

Based on their substrate specificity, CS/DS lyases are subdivided into three types CSase $\mathrm{ABC}, \mathrm{AC}$ and $\mathrm{B}$. The CSase $\mathrm{ABC}$ can digest CS, DS and HA, irrespective of their sulfation/C-5-epimerization pattern. Currently, the CSase ABC from Proteus vulgaris is widely used for GAG structure analysis. The commercially available CSase ABC comprises a mixture of the CSase ABC I (EC 4.2.2.20) with endolytic activity and the CSase ABC II (EC 4.2.2.21) with exolytic activity (Yamagata et al., 1968; Hamai et al., 1997). The CSase AC (EC 4.2.2.5) is highly sensitive to the 5-epimerization of GlcA residues in GAG chains and can act only on CS, HA and CS domains in CS-DS hybrid chains (Yamagata et al., 1968; Hiyama and Okada, 1975; Linhardt et al., 2006), whereas, the CSase B (EC 4.2.2.19) is specifically cleaves DS and DS domains in CS-DS hybrid chains (Yamagata et al., 1968; Gu et al., 1995). The CSase AC I from Flavobacterium heparinum and CSase AC II from Arthrobacter aurescens are well-known CS/DS lyases showing endolytic and exolytic activities, respectively (Yamagata et al., 1968; Hiyama and Okada, 1975). The CSase B from Flavobacterium heparinum is the only commercialized lyase with specific endolytic activity to DS (Yamagata et al., 1968). Notably, the CSase $\mathrm{ABC}$ and CSase $\mathrm{AC}$ belong to the polysaccharide 


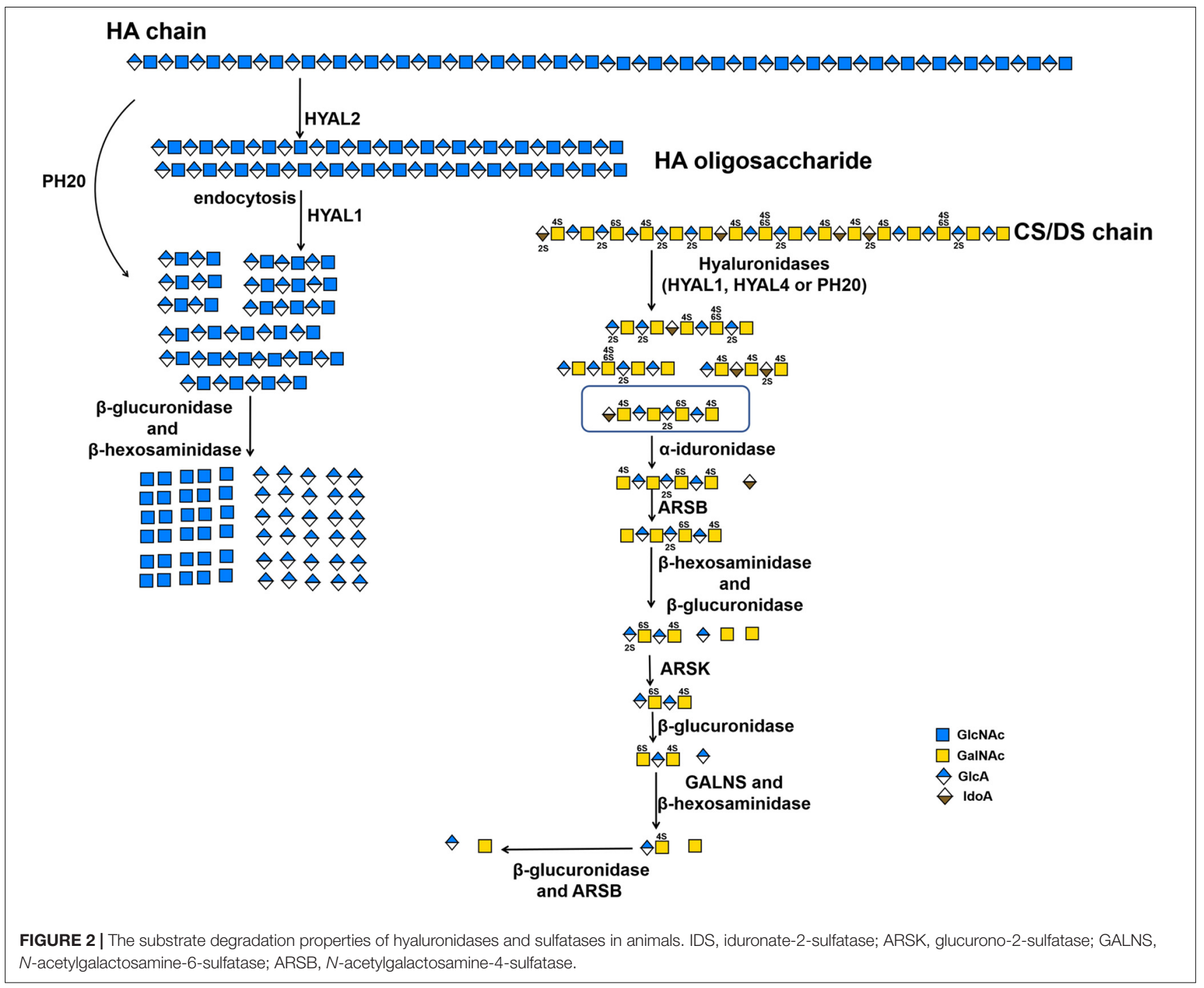

lyase (PL) family 8 , but the CSase B belongs to PL family 6 , which comprises alginate lyases (www.cazy.org) (Figure 3 and Table 2). Structural heterogeneity has hampered structurefunction relationship studies of CS/DS chains. However, there are only a few CS/DS lyases that have been characterized in detail and commercially available, which is far from meeting the needs of CS/DS-related researches and applications.

\section{Newly Identified CS/DS Lyases}

Most recently, some unique CS/DS lyases have been identified in various microorganisms (Table 2). Most of them are CS and HA lyases. Hyaluronidase-B from Bacillus sp. A50 and the hyaluronate lyase BniHL from the deep-sea bacterium Bacillus niacin show endolytic activity towards CS and HA at an approximately neutral pH (Guo et al., 2014; Kurata et al., 2015). A Chn lyase ChoA1 from Arthrobacter sp. MAT3885 can degrade Chn, CS and HA (Kale et al., 2015). Namburi et al. found a CSase AC from Helicobacter bizzozeronii in canine stomach, and this enzyme exhibited specific endolytic activity on HA and various CSs with different sulfation patterns at an optimum low $\mathrm{pH}$ between $\mathrm{pH} 4.0$ and $\mathrm{pH} 5.5$ and might represent one of several factors involved in the development of gastritis in dogs (Namburi et al., 2016). The CSase AsChnAC identified from Arthrobacter sp. SD-04 displays exolytic activity toward HA and various CSs too (Chen et al., 2019). Sugiura et al. identified two highly homologous occlusion-derived variants of virus envelope protein 66s from Autographa californica nucleopolyhedrovirus and Bombyx mori nucleopolyhedrovirus, and both of the variants showed specific lyase activity towards non-sulfated and 6-O-sulfated CS (Sugiura et al., 2011; Sugiura et al., 2013). BtCDH from the human gut microbe Bacteroides thetaiotaomicron belongs to a new PL family (PL29) and shows optimum endolytic activity toward HA and CS, particularly large chains longer than decasaccharide, at a very high temperature of $60{ }^{\circ} \mathrm{C}$ (Ndeh et al., 2018). Two novel CS/DS lyases have been found from Acinetobacter sp. C26 and Sphingomonas paucimobilis, respectively, both of which have lower molecular weights but similar broad-spectrum activities against CS, DS and HA compared with CSase ABC (Zhu et al., 2017; Fu et al., 2018). However, most of these studies have mainly focused on 
TABLE 2 | CS/DS-degrading enzymes from bacteria.

\begin{tabular}{|c|c|c|c|c|c|c|}
\hline Name & Substrate & Source & $\begin{array}{l}\text { Degradation } \\
\text { mechanism }\end{array}$ & Action pattern & EC number (Filmay) & References \\
\hline CSase ABC I & HA, CS or DS & Proteus vulgaris & lysis & endo & EC 4.2.2.20 (PL8) & $\begin{array}{l}\text { Yamagata et al., 1968; Hamai et al., } \\
1997\end{array}$ \\
\hline CSase ABC II & HA, CS or DS & Proteus vulgaris & lysis & $\begin{array}{l}\text { exo (from nonreducing } \\
\text { end) }\end{array}$ & EC 4.2.2.20 (PL8) & $\begin{array}{l}\text { Yamagata et al., 1968; Hamai et al., } \\
1997\end{array}$ \\
\hline CSase AC I & HA or CS & Flavobacterium heparinum & lysis & endo & EC 4.2.2.5 (PL8) & $\begin{array}{l}\text { Yamagata et al., 1968; Gu et al., } \\
1995\end{array}$ \\
\hline CSase AC II & HA or CS & Arthrobacter aurescens & lysis & exo (from reducing end) & EC 4.2.2.5 (PL8) & Lunin et al., 2004; Yin et al., 2016 \\
\hline CSase AC-III & HA or CS & Flavobacterium sp. Hpl02 & lysis & endo & EC 4.2.2.5 (PL8) & Miyazono et al., 1990 \\
\hline CSase C & HA or CSC & Flavobacterium heparinum. & lysis & endo & EC 4.2.2.-(PL8) & Michelacci and Dietrich, 1976 \\
\hline CSase B & DS & Flavobacterium heparinum & lysis & endo & EC 4.2.2.19 (PL6) & $\begin{array}{l}\text { Yamagata et al., 1968; Gu et al., } \\
1995\end{array}$ \\
\hline CSase B II & DS & Flavobacterium sp. Hpl02 & lysis & endo & EC 4.2.2.19 (PL6) & Miyazono et al., 1990 \\
\hline Hyaluronidase-B & HA or CS & Bacillus sp. A50 & lysis & endo & EC 4.2.2.- (PL8) & Guo et al., 2014 \\
\hline AcODV-E66 & HA or CS & Autographa californica nucleopolyhedrovirus & lysis & endo & EC 4.2.2.- (PL8) & Sugiura et al., 2011 \\
\hline BmODV-E66 & HA or CS & Bombyx mori nucleopolyhedrovirus & lysis & endo & EC 4.2.2.- (PL8) & Sugiura et al., 2013 \\
\hline HCLase & HA or CS & Vibrio sp. FC509 & lysis & endo & EC 4.2.2.- (PL8) & Han et al., 2014 \\
\hline HCDLase & HA, CS or DS & Vibrio sp. FC509 & lysis & exo (from reducing end) & EC 4.2.2.- (PL8) & Wang et al., 2017 \\
\hline HCLase Er & HA or CS & Vibrio sp. FC509 & lysis & endo & EC 4.2.2.- (PL8) & (Peng et al., 2018) \\
\hline BniHL & HA or CS & Bacillus niacin & lysis & endo & EC 4.2.2.- (PL8) & Kurata et al., 2015 \\
\hline ChoA1 & HA or CS & Arthrobacter sp. MAT3885 & lysis & endo & EC 4.2.2.- (PL8) & Kale et al., 2015 \\
\hline BtCDH & HA or CS & Bacteroides thetaiotaomicron & lysis & endo & EC 4.2.2.-(PL8) & Ndeh et al., 2018 \\
\hline BHCSase AC & HA or CS & Helicobacter bizzozeronii & lysis & endo & EC 4.2.2.-(PL8) & Namburi et al., 2016 \\
\hline AsChnAC & HA or CS & Arthrobacter sp. SD-04 & lysis & exo (undetermined) & EC 4.2.2.- (PL8) & Chen et al., 2019 \\
\hline HYAL & $\mathrm{HA}$ & Streptomyces hyalurolyticus & lysis & endo & EC 4.2.2.1 (PL8) & Ohya and Kaneko, 1970 \\
\hline HYAL & HA & Streptococcus dysgalactiae & lysis & endo & EC 4.2.2.1 (PL8) & Sting et al., 1990 \\
\hline 4-O-endosulfatase & 4-O-sulfate on GalNAc of CS and DS & Vibrio sp. FC509 & sulfatase & $\begin{array}{l}\text { endo (from reducing } \\
\text { end) }\end{array}$ & EC 3.1.6.- (S1_27) & $\begin{array}{l}\text { Wang et al., 2015; Wang et al., } \\
\text { 2019b }\end{array}$ \\
\hline BT_3349 & 4-O-sulfate on GalNAc of CS and DS & Bacteroides thetaiotaomicron & sulfatase & endo & EC 3.1.6.- (S1_27) & Ulmer et al., 2014 \\
\hline BT_3333 & 6-O-sulfate on GalNAc & Bacteroides thetaiotaomicron & sulfatase & exo (nonreducing end) & EC 3.1.6.- (S1_15) & Ulmer et al., 2014 \\
\hline BT_1596 & $\begin{array}{l}\text { 2-O-sulfate on } \Delta \mathrm{HexA} \text { of } \mathrm{HS} / \mathrm{CS} \\
\text { degradation products }\end{array}$ & Bacteroides thetaiotaomicron & sulfatase & exo (nonreducing end) & EC 3.1.6.- (S1_9) & Ulmer et al., 2014 \\
\hline chondro-4-sulfatase & 4-O-sulfate on GalNAc of CS & Proteus vulgaris & sulfatase & exo (reducing end) & EC 3.1.6.9 (S1_27) & $\begin{array}{l}\text { Yamagata et al., 1968; Sugahara } \\
\text { and Kojima, } 1996\end{array}$ \\
\hline chondro-6-sulfatase & 6-O-sulfate on GalNAc of CS & Proteus vulgaris & sulfatase & exo (reducing end) & EC 3.1.6.10 (S1_15) & $\begin{array}{l}\text { Yamagata et al., 1968; Sugahara } \\
\text { and Kojima, } 1996\end{array}$ \\
\hline $\begin{array}{l}\text { delta-hexuronate-2- } \\
\text { sulfatase }\end{array}$ & $\begin{array}{l}\text { 2-O-sulfate on } \Delta \mathrm{HexA} \text { of HS/CS } \\
\text { degradation products }\end{array}$ & Flavobacterium heparinum & sulfatase & exo (nonreducing end) & EC 3.1.6.- (S1_9) & $\begin{array}{l}\text { Sugahara and Kojima, 1996; } \\
\text { Myette et al., } 2003\end{array}$ \\
\hline PB2SF & $\begin{array}{l}\text { 2-O-sulfate on } \Delta \mathrm{HexA} \text { of HS/CS } \\
\text { degradation products }\end{array}$ & Photobacterium sp. FC615 & sulfatase & exo (reducing end) & EC 3.1.6.- (S1_2) & Wang et al., $2019 a$ \\
\hline exoPB4SF & 4-O-sulfate on CS/DS GalNAc & Photobacterium sp. FC615 & sulfatase & exo (reducing end) & EC 3.1.6.12 (S1_27) & Wang et al., 2019b \\
\hline
\end{tabular}

PL: Polysaccharide lyase family; S: Sulfatase famlily. 


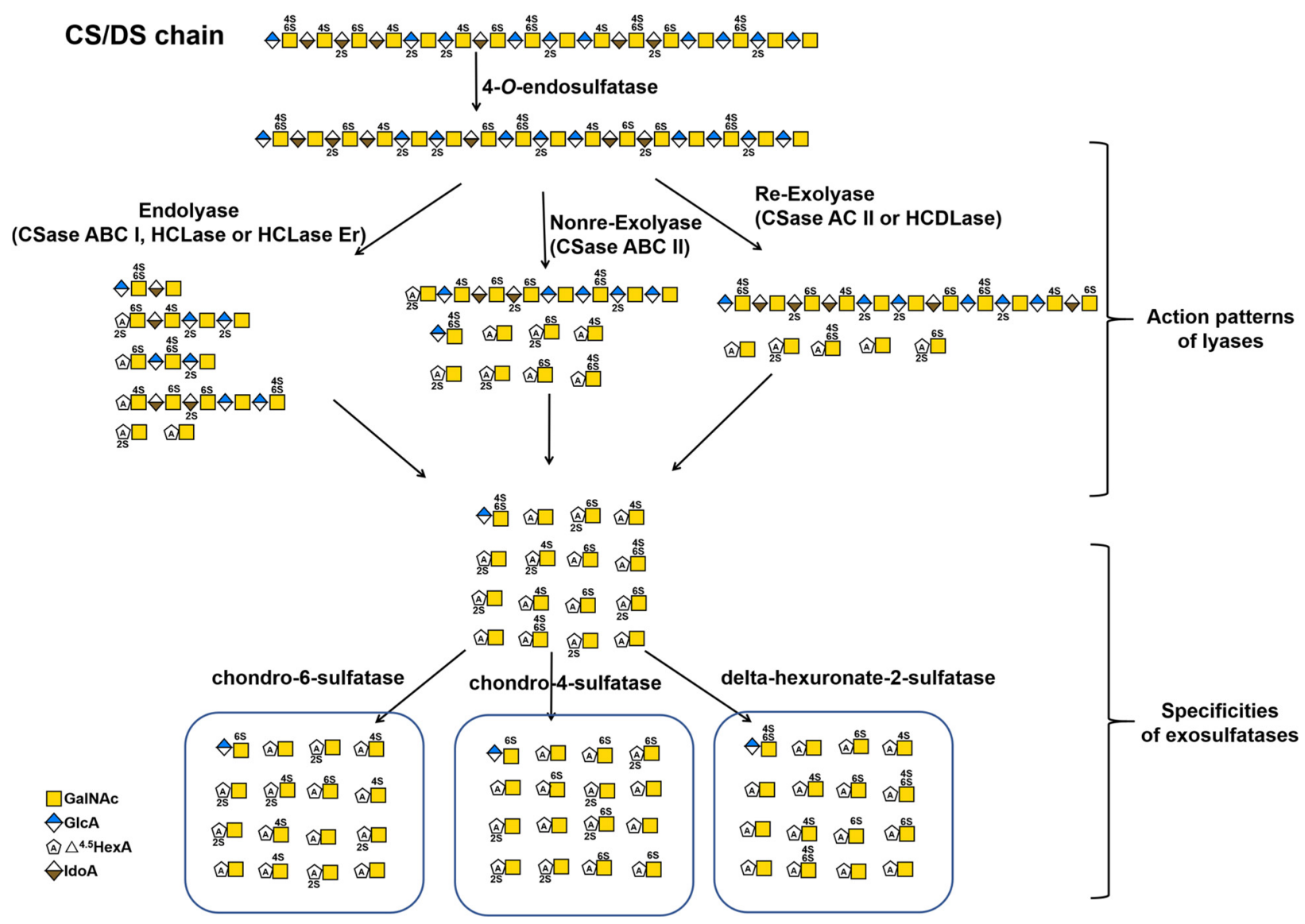

FIGURE 3 | The substrate degradation properties of lyases and sulfatases in bacteria. Nonre-Exolyase, exolyase acted on the nonreducing end of CS/DS chains; Re-Exolyase, exolyase acted on the reducing end of CS/DS chains.

the basic enzymatic properties and rough substrate specificity of these novel CS/DS lyases, and there is a lack of in-depth studies on their substrate-degrading mode and catalytic mechanism of these enzymes.

Marine animals are enriched in CS/DS with unique structures, which indicates that there must be a large number of microorganisms owning corresponding enzymes that would allow them to degrade and utilize these unique CS/DS forms in the ocean. Consistent with our speculation, marine bacteria-derived CS/DS-degrading enzymes show various unique characteristics. HCLase is the first marine-derived CS/DS lyase identified from the bacterium Vibrio sp., which is isolated from sea mud. This enzyme has high endolytic activity towards HA and CS with various sulfation patterns at an approximately neutral $\mathrm{pH}$ and exhibits excellent biochemical characteristics, such as halophilicity, $\mathrm{pH}$ stability and thermal stability. Although HCLase can digest the $\beta$-1,4-glycosidic bond between GalNAc and most disaccharide units, it is unable to act on the galactosaminidic linkage between GalNAc and the D unit, suggesting that the 2-O-sulfation of GlcA inhibits the action of HCLase, which is similar to the case of CSase AC I (Han et al., 2014). In contrast, HCLase Er from the same strain is the first identified CS lyase that is specifically inhibited by both 4-O- and 6-O-sulfation of GalNAc, which is very useful for selectively preparing E unit-rich oligosaccharides from CS polysaccharides (Peng et al., 2018). HCDLase is a novel exotype lyase from the same bacterial strain, which can degrade HA, CS and DS from their reducing end by sequentially releasing unsaturated disaccharides. In particular, it can effectively cleave CS oligosaccharides with reducing ends that are labeled with 2-aminobenzamide (2-AB) to release the 2-AB-labelled reducingend disaccharides, which is a rare activity useful for the enzymatic sequencing of CS chain (Wang et al., 2017). Taken together, these studies suggest that the ocean is an untapped treasure trove of new CS/DS-degrading enzymes.

\section{CS/DS Sulfatases}

The sulfation patterns of CS/DS chains play a key role in various functions of CS/DS. Technically, sulfatases with specific activity that allow them to selectively remove sulfate groups from CS/DS chains should be another important tool for the structural and functional studies of CS/DS. Based on the positions of sulfate groups in CS/DS chains, there are several types of specific sulfatases in animals and bacteria, such as $\mathrm{N}$-acetylgalactosamine-4-O-sulfatase (Yamagata et al., 1968; Sugahara and Kojima, 1996; Wang et al., 2019b; Baum et al., 1959) and $\mathrm{N}$-acetylgalactosamine-6-O-sulfatase (Yamagata et al., 1968; Sugahara and Kojima, 1996; Lim and Horwitz, 1981; Singh et al., 
1976), which specifically hydrolyze sulfate groups on the C-4 and C-6 positions of GalNAc residues, respectively, and hexuronate2-O-sulfatase, which specifically removes $\mathrm{C}-2$ sulfate groups from saturated or unsaturated hexuronic acids derived from the digestion of CS/DS by GAG lyases (Sugahara and Kojima, 1996; Myette et al., 2003; Wang et al., 2019a; Tables 2, 3). Based on the sequence similarities, the GAG sulfatases were recently classified in the database SulfAtlas (http://abims.sb-roscoff.fr/sulfatlas/) (Barbeyron et al., 2016). Animal CS/DS sulfatases are lysosomal enzymes responsible for the degradation of endogenous CS/DS, and genetic defects of these enzymes result in the formation of several mucopolysaccharidoses (MPS) in humans, such as MPS II, MPS IVA and MPS VI (Khan et al., 2017). The wellstudied animal CS/DS sulfatases are $N$-acetylgalactosamine-4$O$ sulfatase (also named Arylsulfatase B, ARSB) (Baum et al., 1959; Wicker et al., 1991), $\mathrm{N}$-acetylgalactosamine-6-O-sulfatase (GALNS) (Lim and Horwitz, 1981; Bielicki and Hopwood, 1991; Tomatsu et al., 1991), iduronate-2-O-sulfatase (IDS) (Lim et al., 1974; Shaklee et al., 1985; Wilson et al., 1990) and Glucurono-2-sulfatase (Arylsulfatase K, ARSK) (Dhamale et al., 2017), which specifically remove the 4-O-sulfate group from sulfated GalNAc residues of CS/DS, 6-O-sulfate group from sulfated GalNAc residues of CS/DS and sulfated galactose of keratan sulfate, 2-O-sulfate groups of sulfate IdoA residues of DS and heparin (Hep), and 2-O-sulfate groups of GlcA residues of heparan sulfate (HS), respectively (Parenti et al., 1997; Tables 2, 3). All these animal CS/DS sulfatases belong to exosulfatases.

In contrast, bacterial CS/DS sulfatases are essential for the biodegradation and utilization of CS/DS from animals, and a large number of potential sulfatase genes have been found in the genomes of various bacteria. However, only a few CS/DS sulfatases have been studied in detail. Three $\Delta^{4,5} \mathrm{HexA}$ 2-O-sulfatases have been identified from Flavobacterium heparinum, Bacteroides thetaiotaomicron and Photobacterium sp. FC615, that can specifically remove 2-O-sulfate ester from a $\triangle$ HexA residue located at the nonreducing terminus of an unsaturated oligosaccharide (Sugahara and Kojima, 1996; Myette et al., 2003; Ulmer et al., 2014; Wang et al., 2019a). Two $\mathrm{N}$-acetylgalactosamine-4-O-sulfatases from Proteus vulgaris and Photobacterium sp. FC615 specifically hydrolyze 4-O-sulfate groups on GalNAc residues at the reducing ends of CS/DS chains (Sugahara and Kojima, 1996; Wang et al., 2019b). An $\mathrm{N}$-acetylgalactosamine-6-O-sulfatase from Proteus vulgaris has been shown to specifically act on 6-O-sulfates on GalNAc residues at the reducing termini of CS/DS oligosaccharides (Sugahara and Kojima, 1996), and another $\mathrm{N}$-acetylgalactosamine-6-Osulfatase from Bacteroides thetaiotaomicron can only attack the 6-O-sulfate group on monosaccharide GalNAc residues (Ulmer et al., 2014). Notably, most of the identified CS/DS sulfatases are exo-type enzymes, which only remove sulfate esters from the ends of CS/DS poly-/oligosaccharides and thus have very limited applications to structural and functional studies of CS/DS. Recently, two endo-type $\mathrm{N}$-acetylgalactosamine-4-Osulfatases were identified from Bacteroides thetaiotaomicron (Ulmer et al., 2014) and Vibrio sp. FC509 (Wang et al., 2015), which can effectively remove 4-O-sulfate groups from GalNAc

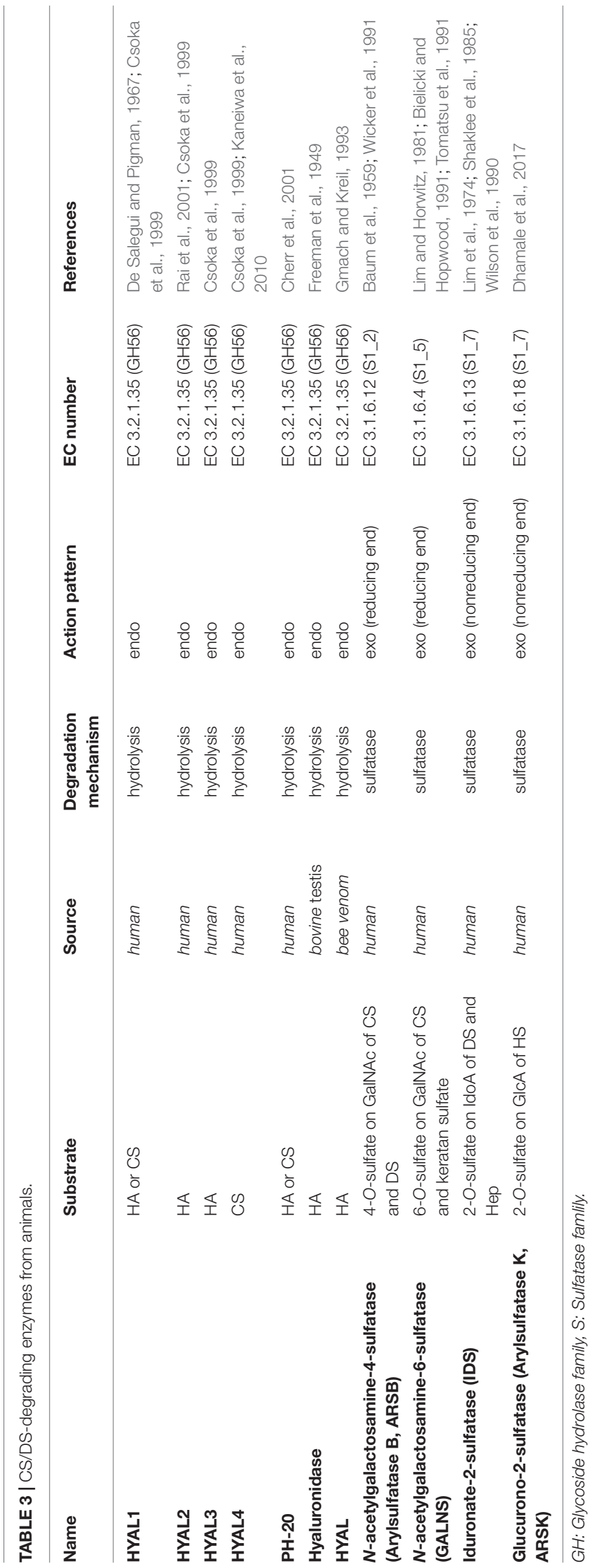


residues within the CS/DS chains (Table 2 and Figures 2, 3). Compared with exosulfatases, endosulfatases should be more useful enzymatic tools for CS/DS studies but seem to be very rare in nature. Our recent study has shown that CS/DS sulfatases with similar specificities have common signature sequences and can cluster to form a single branch in the phylogenetic tree, although they descended from separate ancestral genes (Wang et al., 2019a). Based on this finding, a series of $\Delta^{4,5} \mathrm{HexA}$ 2-O-sulfatases have been successfully predicted and verified from sequences in GenBank (Wang et al., 2019a), and we believe that some CS/DS endosulfatases could also be found by using this method. In fact, the existence of endosulfatases facilitates the catabolic metabolism of CS/DS by bacteria, in which the degradation of CS/DS chains by lyases can be significantly promoted via pre-desulfation by endosulfatases (Wang et al., 2015).

\section{APPLICATIONS IN CS/DS STRUCTURE-FUNCTION STUDIES}

Their great structural heterogeneity endows CS/DS chains with various functions but also poses a great challenge to the structure-function studies of CS/DS. A growing body of research shows that CS/DS chains function through interacting with target proteins and that some oligosaccharide domains with specific structural features in CS/DS chains are involved in these interactions (Sugahara et al., 2003; Raman et al., 2005; Kastana et al., 2019; Pudelko et al., 2019). Thus, it is key for studying the structure and function of CS/DS to investigate the structural features in particular functional domains of the CS/DS chains involved in an interaction with a specific target protein. CS/DS-degrading enzymes with different specific activities play irreplaceable tools in such studies (Linhardt et al., 2006; Li et al., 2010; Wang et al., 2017).

\section{Compositional Analysis of CS/DS}

As a kind of highly heterogeneous polysaccharides, the exact structures of all the chains in CS/DS samples cannot be determined with current technology. Thus, the disaccharide composition is used as a basic parameter to characterize various CS/DS preparations used in basic studies and industrial production. Commercial CS/DS preparations are extracted from terrestrial and marine sources, such as the cartilages from bovine, porcine, chicken, shark and squid, and are wildly used in medicines and health products (Bao et al., 2005; Deepa et al., 2007a; Volpi, 2007, 2009; Valcarcel et al., 2017). However, the biological and pharmacological properties of these CS/DS preparations are seriously affected by the raw materials, manufacturing processes and many other factors impacting their production. Disaccharide analysis has been commonly used to evaluate the quality of CS/DS products. CS/DS lyases play a key role in disaccharide composition assays of CS/DS. In general, the disaccharide compositions of various forms of CS/DS with different sulfation patterns can be easily determined by digestion with the commercial CSase ABC followed by anion-exchange HPLC. However, digestion by CSase ABC causes the conversion of both GlcA and IdoA residues into unsaturated uronic acid and thus CS and DS in the test sample cannot be distinguished by this method. In this case, we can use the substrate specificity of the CSase AC and CSase B to investigate the disaccharide composition and proportions of CS and DS in samples.

For example, to determine the disaccharide composition of CS/DS extracted from shark liver, we used CSases that differed in their specificity (CSase ABC, mixture of CSase AC-I and CSase AC-II or CSase B) to digest the sample, and then the digests were labeled with $2-\mathrm{AB}$ and analyzed by anion exchange HPLC on an amine-bound silica PA- 03 column using a solvent system of 16 and $530 \mathrm{mM} \mathrm{NaH}{ }_{2} \mathrm{PO}_{4}$ over a period of $1 \mathrm{~h}$ by fluorescent detection. Although the shark liver-derived CS/DS preparation contained highly heterogenous hybrid chains of CSDS, the disaccharide composition and contents of CS and DS domains in the hybrid chains could be well determined by this method (Li et al., 2007). In summary, CSases with different substrate specificities play an important role in the disaccharide composition assays of CS/DS.

\section{Preparation of Oligosaccharides With Specific Activity}

The various biological functions of CS/DS are thought to be due to their functional domains, some oligosaccharide sequences with specific structural features. For a specific target protein, the functional domains of CS/DS chains are usually not a single specific structure but some oligosaccharide domains with similar characteristics, such as a minimum size requirement and the enrichment of specific oversulfated disaccharide units (Trowbridge and Gallo, 2002; Trowbridge et al., 2002; Sugahara et al., 2003; Sugahara and Mikami, 2007; Li et al., 2010). Therefore, isolation of the functional oligosaccharide domains from CS/DS chains is key to not only structure-function relationship studies of CS/DS but also the preparation of functional oligosaccharides with specific activities. Compared with the harsh conditions of chemical and physical methods, the enzymatic method is mild and biocompatible for degrading CS/DS to prepare the functional domains. In general, functional oligosaccharides with specific activity can be obtained through the partial digestion of CS/DS chains with specific enzymes followed by a series of chromatographic separations, especially affinity chromatography. Various CS/DS glycosidic bond-cleaving enzymes, including hyaluronidases and lyases, have been used to prepare CS/DS oligosaccharides. As mentioned above, the CS/DS oligosaccharides produced by lyases bear an unsaturated 4,5-bond between C-4 and C-5 of $\triangle \mathrm{HexA}$ at their nonreducing ends, which can be easily detected at $232 \mathrm{~nm}$. Moreover, CS/DS lyases show more flexibility in terms of substrate specificity. Thus, CS/DS lyases, including CSase ABC, AC I and B, have been widely used to partially digest various forms of CS/DS for preparing functional oligosaccharides that specifically bind to certain proteins (Fukui et al., 2002; Bao et al., 2005; Kim et al., 2017; Li et al., 2007). In contrast, glycan arrays have the advantages of low dosage, high sensitivity, high throughput, and rapid analysis, which is suitable for the large-scale 
screening and investigation of potential biological functions of various glycans and their conjugates including CS/DS poly- and oligosaccharides (Fukui et al., 2002). By using this technique, E unit-rich polysaccharides and structure-defined tetrasaccharides have been shown to interact with TNF- $\alpha$ (Tully et al., 2006), bFGF (Miyachi et al., 2015), and midkinederived and brain-derived neurotrophic factor (Gama et al., 2006) with high affinity. Moreover, this method was used to investigate the interaction between DS and its binding proteins (Yamaguchi et al., 2006). Thus, glycan arrays can be very a powerful tool for the identification of novel functions of CS/DS oligosaccharides with different structures derived from the digestion of CS/DS polysaccharides with various degrading enzymes.

The selective degradation of inactive domains is an ideal way to isolate functional oligosaccharides from CS/DS polysaccharides. Technically, this can be achieved by selecting enzymes with a certain substrate specificity. For example, in a previous study we found that shark skin/liver-derived CS/DS could strongly interact with PTN and HGF to promote neurite outgrowth and this activity could be abolished by treatment with the CSase B but not the CSase AC I. Based on this finding, a PTN- and HGF-binding hexasaccharide containing two iB units was eventually isolated from shark skin CS/DS through selective digestion with the CSase AC I followed by pleiotrophin affinity and anion exchange chromatographies (Li et al., 2007, 2010). In addition to the different selectivity of the CSase AC and B toward uronic acid epimers, some enzymes show high sensitivity to specific sulfation patterns of CS/DS chains, which is important for the preparation of oligosaccharides with specific structures, such as E unitrich oligosaccharides, which play a key role in neuronal cell adhesion and outgrowth (Ueoka et al., 2000; Mikami et al., 2009; Nandini and Sugahara, 2006; Purushothaman et al., 2007), cancer cell metastasis (Li et al., 2008; Mizumoto et al., 2012, 2013b) and virus infections (Bergefall et al., 2005; Kato et al., 2010), and D unit-rich oligosaccharides, which significantly promote hippocampal neurite outgrowth through interacting with various growth factors and other proteins (Nandini and Sugahara, 2006; Clement et al., 1998; Shida et al., 2019). Testicular hyaluronidase can efficiently digest non-sulfated and low sulfated domains but not highly sulfated domains in CS chains, which makes it a good choice for the selective isolation of highly sulfated domains from CS/DS chains, such as the preparation of D unit-rich oligosaccharides from CS-D (Nadanaka and Sugahara, 1997) and E unit-rich oligosaccharides from CS-E (Kinoshita et al., 2001), respectively. Furthermore, our studies have shown that HCLase like CSase AC I cannot cleave the $\beta$-1,4-linkage between GalNAc and D unit (Han et al., 2014), and in contrast, HCLase Er cannot efficiently act on the $\beta$-1,4-linkage between $\mathrm{E}$ unit and GlcA (Peng et al., 2018), which makes these enzymes more specific tools for the selective isolation of $\mathrm{D}$ unit-rich domains and $\mathrm{E}$ unitrich domains in CS/DS chains. Figure 4 shows a schematic diagram of the preparation of various structurally determined hexasaccharides by CS/DS degradation of enzymes with specific activities. In addition, various CS/DS sulfatases combined with sulfotransferases can be potential tools to further edit the sulfation pattern of the obtained oligosaccharides for functional evaluation (Li et al., 2017; Shioiri et al., 2016; Wang et al., 2015; Wang et al., 2019b). Recently, Li et al. developed a method to synthesize CS oligosaccharides using multiple glycosyltransferases and sulfotransferases, and synthesized 15 homogeneous CS oligosaccharide by this method ( $\mathrm{Li}$ et al., 2017). However, the de novo synthesis of CS/DS oligosaccharides is very cumbersome, heavy workload, time-consuming and costly. By contrast, it can be a relatively simple, efficient and low-cost choice to prepare basic oligosaccharide structures from CS/DS polysaccharides by treatment with various degrading enzymes and further modify these basic structures with specific synthetases to prepare structure-defined oligosaccharides (Cai et al., 2012; Zhang et al., 2019).

In brief, CS/DS-degrading enzymes, including hydrolases, lyases and sulfatases, are very useful tools for preparing functional oligosaccharides with specific structures from CS/DS polysaccharides. With the identification of an increasing number of enzymes with novel substrate specificity, the directional isolation and preparation of oligosaccharides with specific structures from various CS/DS forms will be achieved, which may represent a more feasible and low-cost way to prepare CS/DS oligosaccharides with specific bioactivity compared with synthetic methods.

\section{Sequencing of CS/DS Oligosaccharides}

Sequencing of the isolated functional oligosaccharides with special structures is essential for structure-function studies of CS/DS. Various methods, such as NMR and MS, have been used to determine the structures of CS/DS oligosaccharides. Ly et al. reported successful sequencing of bikunin CS chains with up to 43 saccharide units with FT-ICR-MS/MS (Ly et al., 2011). It is still difficult to distinguish different units with the same sulfation degree, such as monosulfated A and C units or disulfated $\mathrm{D}$ and $\mathrm{E}$ units. Meanwhile, the distinction of hexuronate epimers and the loss of sulfate groups during analysis are also major challenges. In addition, instrument requirements formethods using NMR and MS are more sophisticated, and NMR, in particular, requires a much greater amount of sample. Sugahara lab has developed a method to analyze and monitor CS/DS oligosaccharides with highly sensitively via the fluorescent labelling of reducing ends with $2-\mathrm{AB}$ followed by anion exchange HPLC, and the detection limit for 2-ABoligosaccharides is as low as 1 pmol (Kinoshita and Sugahara, 1999). However, further study showed that the 2-AB labelling completely inhibited the cleavage of the $\beta$-1,4- linkage in the tetrasaccharide at the reducing end of the CS/DS chain by CSase ABC (Kinoshita and Sugahara, 1999). Whereas, in most cases, some exolyases, such as CSase AC II and HCDLase, can effectively degrade 2-AB-labelled $\mathrm{CS}$ oligosaccharides to release the 2AB-labelled reducing-end disaccharides. By taking advantage of these characteristics of enzymes, CS/DS oligosaccharides that are shorter than decasaccharides can be easily sequenced by enzymatic methods (Bao et al., 2005; Deepa et al., 2007b). Recently, we exploited a novel exolyase HCDLase combined with CSase $\mathrm{ABC}$ to sequence a complex octasaccharide 


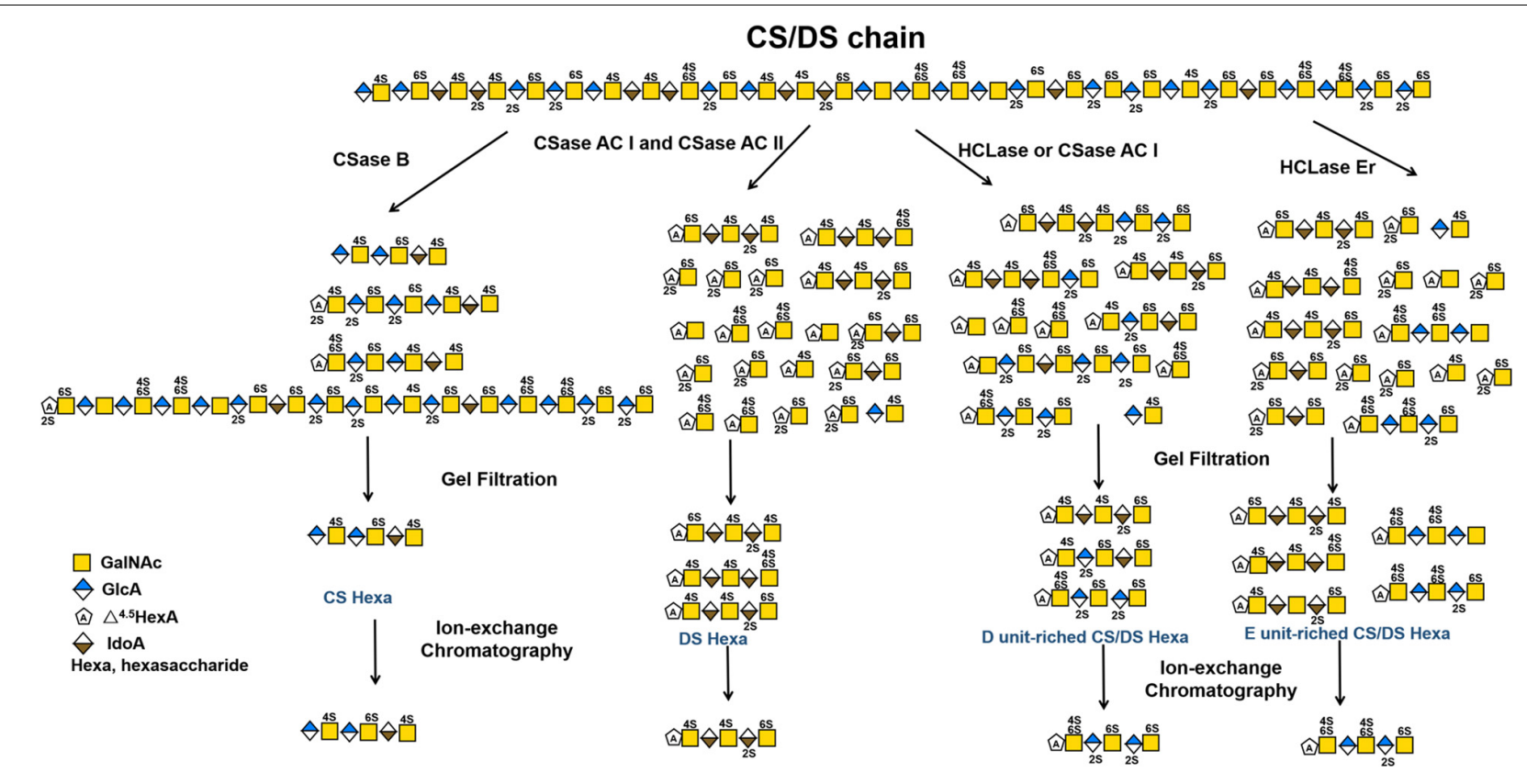

FIGURE 4 | Schematic diagram of preparation of various structure-defined hexasaccharides by CS/DS-degrading enzymes with specific activity.

( $\Delta$ C-A-D-C) (Wang et al., 2017). In this method, the disaccharide composition of the octasaccharide was determined by digestion with the CSase $\mathrm{ABC}$ followed by 2-AB labelling and HPLC assay. Then, the octasaccharide was labeled with $2-\mathrm{AB}$ and partially digested with CSase $\mathrm{ABC}$ to prepare the 2-AB-labelled reducing-end hexasaccharides. The reducing-end $\mathrm{C}$ unit can be directly determined through the digestion of the 2-ABlabelled octasaccharide with HCDLase followed by HPLCfluorescence detection. To determine the first and second disaccharide units from the nonreducing terminus, the 2AB-labelled octasaccharide and reducing-end hexasaccharide prepared as described above were individually digested by the CSase ABC and analyzed by HPLC after relabelling with 2$\mathrm{AB}$. This strategy is theoretically feasible for sequencing longer oligosaccharides but is not easy to achieve due to the rapid increase in operating steps with the increase of saccharide chains. Moreover, Shioiri et al. developed an enzymatic method for the sequencing of a synthesized CS dodecasaccharide (C$\mathrm{C}-\mathrm{O}-\mathrm{A}-\mathrm{O}-\mathrm{O})$ by using a strategy involving dual-fluorescence labelling and dual-digestion (Shioiri et al., 2016). This provides a possibility of sequencing longer CS/DS oligosaccharides. However, the inability of testicular hyaluronidase to cleave DS and highly sulfated CS limits the application of this method, and thus, it is necessary to find alternative enzymes with better features.

\section{Potential Medical Applications}

The abnormal expression of CS/DS has been shown to be closely related to the occurrence and development of various diseases, such as glial scar formation after brain injury, tumor metastasis, skeletal disorder and viral infection, indicating that the treatment with CS/DS-degrading enzymes should affect the progression of the related diseases and these enzymes might be used as therapeutic agent for the related diseases. In the research of a spinal cord injury (SCI) model, Lemons et al. expounded that CSPGs increased in the lesion and inhibited the growth of axons, that is, inhibited the recovery of the function of the lesion (Lemons et al., 1999; Mondello et al., 2015). Injecting of CSase $\mathrm{ABC}$ induces abnormal axon growth or enhance axon regeneration in zebrafish (Bernhardt and Schachner, 2000; Becker and Becker, 2002), adult rats (Bradbury et al., 2002; Janzadeh et al., 2017; Moon et al., 2001), mice (Li et al., 2013), and cats (Mondello et al., 2015). Moreover, CSase ABC combined with other operations such as human adipose derived stem cells (Sarveazad et al., 2017) or low level laser therapy (Janzadeh et al., 2017) can promote the treatment of SCI. Additionally,CSase ABC is used to treat some diseases related to nerve damage, such as glaucoma (Tribble et al., 2018), lumber intervertebral disc (Hoogendoorn et al., 2007; Sugimura et al., 1996; Lü et al., 1997), and to delay the progress of Parkinson's disease (Kauhausen et al., 2015) and Alzheimer's disease (Howell et al., 2015). Overall, these studies suggest that CS/DS-degrading enzymes, in particular CSase ABC with broad substrate spectrum, are very promising therapeutic agents for the treatment of nerve injury-related diseases. Most recently, studies have also found that 4-O-sulfated CS GAG chains are increased significantly at the injury site after SCI (Wang et al., 2008) and optic nerve injury (Pearson et al., 2018). ARSB, a mammalian 4$O$-sulfatase, treatment improves locomotor function recovery after SCI (Yoo et al., 2013) and improves regeneration after optic nerve injury (Pearson et al., 2018). Comparing with the exo-sulfatases, the newly discovered 4-O-endosulfatases may show better effect in nerve injury repair, which remains to be investigated. 
The abnormal expression of CS/DS or CS/DSPGs in cells and tissues is closely related to many tumorigenic processes including cell growth and survival, adhesion, migaration and invasion (Theocharis et al., 2010; Iozzo and Sanderson, 2011; Li et al., 2008). A series of studies have shown that CSases have potential application value in anti-tumor. For example, CSase $\mathrm{ABC}$ and CSase AC could significantly inhibited the growth of tumor while streptomyces hyaluronidase, and $\beta$-glucuronidase could not (Takeuchi, 1972), CSase AC and CSase B can inhibits the invasion and proliferation of melanoma (Denholm et al., 2001), CSase ABC can assist temozolomide in the treatment of glioblastoma (Jaime-Ramirez et al., 2017), the adhere ability of squamous tongue carcinoma SCC-9 LN-1 cells can be reduced by treatment with CSaseABC (Kawahara et al., 2014), the metastasis of Lewis lung carcinoma LM66H11 cells can be effectively inhibited by treatment with CSase ABC ( $\mathrm{Li}$ et al., 2008), and so on (Sullivan et al., 2018). Moreover, Link et al. found that treatment with CSase $\mathrm{ABC}$ enhanced integration of both immature and mature self-assembled articular cartilage to native tissue, indicating that Case $\mathrm{ABC}$ has a potential therapeutic target for the integration of neocartilage (Link et al., 2020). In fact, some hyaluronidases, such as ovine testicles hyaluronidase (Vitrase ${ }^{\circledR}$ ), bovine testicular hyaluronidase (Hydase ${ }^{\mathrm{TM}}$ ) and recombinant human hyaluronidase PH20 (ENHANZE ${ }^{\circledR}$ ), have been clinically used in ophthalmic surgery (Sarvela et al., 1994) and in cosmetic dermatosurgery for the treatment of complications caused by filler injection (Hirsch et al., 2007).

Additionally, the lack of sulfatase leads to the longterm accumulation of highly sulfated oligosaccharides in the lysosome, which cause lysosomal storage disorders MPSs. MPSII (Hunter, OMIM 309900), MPS IVA (Morquio A, OMIM 253000) and MPS VI (Maroteaux-Lamy, OMIM 253200) resulted from the deficiencies of IDS, GALNS and ARSB, respectively (Bondeson et al., 1995; Matalon et al., 1974; Dorfman et al., 1976). Enzyme replacement therapy is the standard treatment option for MPSs, which can start treatment immediately and improve prognosis. Recombinant human IDS (idursulfase and idursulfase beta), GALNS (elosulfase alfa) and ARSB (galsulfase) are clinically used to treat the corresponding MPSs (Whiteman and Kimura, 2017; Sawamoto et al., 2020; Harmatz and Shediac, 2017). Hematopoietic stem cell transplantation is also available for MPSs treatment (Coppa et al., 1995; Mullen et al., 2000). Moreover, gene therapy should be

\section{REFERENCES}

Afify, A. M., Stern, M., Guntenhoener, M., and Stern, R. (1993). Purification and characterization of human serum hyaluronidase. Arch. Biochem. Biophys. 305, 434-441. doi: 10.1006/abbi.1993.1443

Almeida, R., Levery, S. B., Mandel, U., Kresse, H., Schwientek, T., Bennett, E. P., et al. (1999). Cloning and expression of a proteoglycan UDP-galactose:betaxylose beta1,4-galactosyltransferase I. A seventh member of the human beta4galactosyltransferase gene family. J. Biol. Chem. 274, 26165-26171. doi: 10. 1074/jbc.274.37.26165

Bai, X., Wei, G., Sinha, A., and Esko, J. D. (1999). Chinese hamster ovary cell mutants defective in glycosaminoglycan assembly and glucuronosyltransferase I. J. Biol. Chem. 274, 13017-13024. doi: 10.1074/jbc.274.19.13017 another potential choice for MPSs (Sawamoto et al., 2018; Ponder and Haskins, 2007).

However, the clinical application of CS/DS-degrading enzymes still faces many problems such as immunogenicity, instability and low activity in vivo, which need further study to solve.

\section{CONCLUSION}

Undoubtedly, CS/DS-degrading enzymes with various specific activities play indispensable roles in structural and functional studies as well as other applications related to CS/DS, such as disaccharide composition analysis, quality control of products, preparation of bioactive oligosaccharides, and oligosaccharide sequencing. However, the types and numbers of well-characterized enzymes currently are far from meeting the needs of the research and applications of CS/DS. Therefore, it is an urgent task to identify more CS/DS-degrading enzymes with novel specific activity and to carry out reexamination of old enzymes whose action patterns remain to be investigated in detail.

\section{AUTHOR CONTRIBUTIONS}

WW, LS, and YQ collected the literature, wrote the manuscript, and made the figures. FL conceptualized, edited and made significant revisions to the manuscript. All authors read and approved the final manuscript.

\section{FUNDING}

This work was supported by the National Natural Science Foundation of China (Nos. 31971201, 31570071, and 31800665), the National Natural Science Foundation of Shandong Province (No. ZR2018BC013), the Science and Technology Development Project of Shandong Province (No. 2018GSF121002), the Major Scientific and Technological Innovation Project (MSTIP) of Shandong Province (2019JZZY010817), the General Financial Grant from China Postdoctoral Science Foundation Grant (No. 2019M662343), and the Project of Taishan Industry Leading Talent of Shandong Province (tscy20160311).

Bai, X., Zhou, D., Brown, J. R., Crawford, B. E., Hennet, T., and Esko, J. D (2001). Biosynthesis of the linkage region of glycosaminoglycans: cloning and activity of galactosyltransferase II, the sixth member of the beta 1,3galactosyltransferase family (beta 3GalT6). J. Biol. Chem. 276, 48189-48195. doi: 10.1074/jbc.m107339200

Bao, X. F., Muramatsu, T., and Sugahara, K. (2005). Demonstration of the pleiotrophin-binding oligosaccharide sequences isolated from chondroitin sulfate/dermatan sulfate hybrid chains of embryonic pig brains. J. Biol. Chem. 280, 35318-35328. doi: 10.1074/jbc.m507304200

Barbeyron, T., Brillet-Guéguen, L., Carré, W., Carrière, C., Caron, C., Czjzek, M., et al. (2016). Matching the diversity of sulfated biomolecules: creation of a classification database for sulfatases reflecting their substrate specificity. PLoS One 11:e0164846. doi: 10.1371/journal.pone.0164846 
Baum, H., Dodgson, K. S., and Spencer, B. (1959). The assay of arylsulphatases A and B in human urine. Clin. Chim. Acta 4, 453-455. doi: 10.1016/00098981(59)90119-6

Bearpark, T. M., and Stirling, J. L. (1978). A difference in the specificities of human liver $\mathrm{N}$-acetyl-beta-hexosaminidase A and B detected by their activities towards glycosaminoglycan oligosaccharides. Biochem. J. 173, 997-1000. doi: 10.1042/bj1730997

Becker, C. G., and Becker, T. (2002). Repellent guidance of regenerating optic axons by chondroitin sulfate glycosaminoglycans in zebrafish. J. Neurosci. 22, 842-853. doi: 10.1523/jneurosci.22-03-00842.2002

Bergefall, K., Trybala, E., Johansson, M., Uyama, T., Naito, S., Yamada, S., et al. (2005). Chondroitin sulfate characterized by the E-disaccharide unit is a potent inhibitor of herpes simplex virus infectivity and provides the virus binding sites on gro2C cells. J. Biol. Chem. 280, 32193-32199. doi: 10.1074/jbc.m503645200

Bernhardt, R. R., and Schachner, M. (2000). Chondroitin sulfates affect the formation of the segmental motor nerves in zebrafish embryos. Dev. Biol. 221, 206-219. doi: 10.1006/dbio.2000.9673

Bielicki, J., and Hopwood, J. J. (1991). Human liver N-acetylgalactosamine 6sulphatase. Purification and characterization. Biochem. J. 279(Pt 2), 515-520. doi: $10.1042 /$ bj2790515

Bondeson, M. L., Dahl, N., Malmgren, H., Kleijer, W. J., Tönnesen, T., Carlberg, B. M., et al. (1995). Inversion of the IDS gene resulting from recombination with IDS-related sequences is a common cause of the Hunter syndrome. Hum. Mol. Genet. 1995, 615-621. doi: 10.1093/hmg/4.4.615

Bradbury, E. J., Moon, L. D., Popat, R. J., King, V. R., Bennett, G. S., Patel, P. N., et al. (2002). Chondroitinase $A B C$ promotes functional recovery after spinal cord injury. Nature 416, 636-640.

Bülow, H. E., and Hobert, O. (2006). The molecular diversity of glycosaminoglycans shapes animal development. Annu. Rev. Cell. Dev. Biol. 22, 375-407. doi: 10.1146/annurev.cellbio.22.010605.093433

Cai, C., Solakyildirim, K., Yang, B., Beaudet, J. M., Weyer, A., Linhardt, R. J., et al. (2012). Semi-synthesis of chondroitin sulfate-E from chondroitin sulfate-A. Carbohydr. Polym. 87, 822-829. doi: 10.1016/j.carbpol.2011.08.075

Campo, G. M., Avenoso, A., Campo, S., D’Ascola, A., Traina, P., Samà, D., et al. (2009). Glycosaminoglycans modulate inflammation and apoptosis in LPS-treated chondrocytes. J. Cell Biochem. 106, 83-92. doi: 10.1002/jcb.21981

Chen, L.-Z., Shi, C.-Q., Yin, F.-X., Wang, F.-S., and Sheng, J.-Z. (2019). Cloning and characterization of a chondroitin AC exolyase from Arthrobacter sp. SD-04. Mol. Biotechnol. 61, 791-800. doi: 10.1007/s12033-019-00208-z

Cherr, G. N., Yudin, A. I., and Overstreet, J. W. (2001). The dual functions of GPI-anchored PH-20: hyaluronidase and intracellular signaling. Matrix. Biol. 20, 515-525. doi: 10.1016/s0945-053x(01)00171-8

Chiricozzi, E., Niemir, N., Aureli, M., Magini, A., Loberto, N., Prinetti, A., et al. (2014). Chaperone therapy for GM2 gangliosidosis: effects of pyrimethamine on $\beta$-hexosaminidase activity in Sandhoff fibroblasts. Mol. Neurobiol. 50, 159-167. doi: 10.1007/s12035-013-8605-5

Clement, A. M., Nadanaka, S., Masayama, K., Mandl, C., Sugahara, K., and Faissner, A. (1998). The DSD-1 carbohydrate epitope depends on sulfation, correlates with chondroitin sulfate D motifs, and is sufficient to promote neurite outgrowth. J. Biol. Chem. 273, 28444-28453. doi: 10.1074/jbc.273.43.28444

Coppa, G. V., Gabrielli, O., Zampini, L., Pierani, P., Giorgi, P. L., Jezequel, A. M., et al. (1995). Bone marrow transplantation in Hunter syndrome (mucopolysaccharidosis type II): two-year follow-up of the first Italian patient and review of the literature. Pediatr. Med. Chir. 17, 227-235.

Csoka, A. B., Frost, G. I., and Stern, R. (2001). The six hyaluronidase-like genes in the human and mouse genomes. Matrix. Biol. 20, 499-508. doi: 10.1016/s0945053x(01)00172-x

Csoka, A. B., Scherer, S. W., and Stern, R. (1999). Expression analysis of paralogous human hyaluronidase genes clustered on chromosomes 3 p21 and 7q31. Genomics 60, 356-361. doi: 10.1006/geno.1999.5876

De Salegui, M., and Pigman, W. (1967). The existence of an acid-active hyaluronidase in serum. Arch. Biochem. Biophys. 120, 60-67. doi: 10.1016/ 0003-9861(67)90598-x

Deepa, S. S., Kalayanamitra, K., Ito, Y., Kongtawelert, P., Fukui, S., Yamada, S., et al. (2007a). Novel sulfated octa- and decasaccharides from squid cartilage chondroitin sulfate E: sequencing and application for determination of the epitope structure of the monoclonal antibody MO-225. Biochemistry 46, 24532465. doi: 10.1021/bi602374m
Deepa, S. S., Yamada, S., Fukui, S., and Sugahara, K. (2007b). Structural determination of novel sulfated octasaccharides isolated from chondroitin sulfate of shark cartilage and their application for characterizing monoclonal antibody epitopes. Glycobiology 17, 631-645. doi: 10.1093/glycob/cwm021

Denholm, E. M., Lin, Y. Q., and Silver, P. J. (2001). Anti-tumor activities of chondroitinase AC and chondroitinase B: inhibition of angiogenesis, proliferation and invasion. Eur. J. Pharmacol. 416, 213-221. doi: 10.1016/ s0014-2999(01)00884-6

Dhamale, O. P., Lawrence, R., Wiegmann, E. M., Shah, B. A., Al-Mafraji, K., Lamanna, W. C., et al. (2017). Arylsulfatase K is the lysosomal 2sulfoglucuronate sulfatase. ACS Chem. Biol. 12, 367-373. doi: 10.1021/ acschembio.6b01033

Dorfman, A., Arbogast, B., and Matalon, R. (1976). The enzymic defects in Morquio and Maroteaux-Lamy syndrome. Adv. Exp. Med. Biol. 68, 261-276. doi: 10.1007/978-1-4684-7735-1_18

Evers, M. R., Xia, G., Kang, H. G., Schachner, M., and Baenziger, J. U. (2001). Molecular cloning and characterization of a dermatan-specific $\mathrm{N}$-acetylgalactosamine 4-O-sulfotransferase. J. Biol. Chem. 276, 36344-36353. doi: $10.1074 /$ jbc.m105848200

Freeman, M. E., Anderson, P., Oberg, M., and Dorfman, A. (1949). Preparation of purified hyaluronidase from bovine testis. J. Biol. Chem. 180, 655-662.

Fu, J., Jiang, Z., Chang, J., Han, B., Liu, W., and Peng, Y. (2018). Purification, characterization of Chondroitinase $\mathrm{ABC}$ from Sphingomonas paucimobilis and in vitro cardiocytoprotection of the enzymatically degraded CS-A. Int. J. Biol. Macromol. 115, 737-745. doi: 10.1016/j.ijbiomac.2018.04.117

Fujikawa, S., Ohmae, M., and Kobayashi, S. (2005). Enzymatic synthesis of chondroitin 4-sulfate with well-defined structure. Biomacromolecules 6, 29352942. doi: $10.1021 / \mathrm{bm} 050364 \mathrm{p}$

Fukui, S., Feizi, T., Galustian, C., Lawson, A. M., and Chai, W. G. (2002). Oligosaccharide microarrays for high-throughput detection and specificity assignments of carbohydrate-protein interactions. Nat. Biotechnol. 20, 10111017. doi: $10.1038 / \mathrm{nbt} 735$

Fukuta, M., Kobayashi, Y., Uchimura, K., Kimata, K., and Habuchi, O. (1998). Molecular cloning and expression of human chondroitin 6-sulfotransferase. Biochim. Biophys. Acta 1399, 57-61. doi: 10.1016/s0167-4781(98)00089-x

Gama, C. I., Tully, S. E., Sotogaku, N., Clark, P. M., Rawat, M., Vaidehi, N., et al. (2006). Sulfation patterns of glycosaminoglycans encode molecular recognition and activity. Nat. Chem. Biol. 2, 467-473. doi: 10.1038/nchembio810

Gmach, M., and Kreil, G. (1993). Bee venom hyaluronidase is homologous to a membrane protein of mammalian sperm. Proc. Natl. Acad. Sci. U.S.A. 90, 3569-3573. doi: 10.1073/pnas.90.8.3569

Götting, C., Kuhn, J., and Kleesiek, K. (2007). Human xylosyltransferases in health and disease. Cell. Mol. Life Sci. 64, 1498-1517. doi: 10.1007/s00018-007-7069-z

Götting, C., Kuhn, J., Zahn, R., Brinkmann, T., and Kleesiek, K. (2000). Molecular cloning and expression of human UDP-D-Xylose:proteoglycan core protein beta-d-xylosyltransferase and its first isoform XT-II. J. Mol. Biol. 304, 517-528. doi: $10.1006 /$ jmbi.2000.4261

Gu, K., Linhardt, R. J., Laliberte, M., and Zimmermann, J. (1995). Purification, characterization and specificity of chondroitin lyases and glycuronidase from Flavobacterium heparinum. Biochem. J. 312, 569-577. doi: 10.1042/bj3120569

Guo, X., Shi, Y., Sheng, J., and Wang, F. (2014). A novel hyaluronidase produced by Bacillus sp. A50. PLoS One 9:e94156. doi: 10.1371/journal.pone.0094156

Gushulak, L., Hemming, R., Martin, D., Seyrantepe, V., Pshezhetsky, A., and Triggs-Raine, B. (2012). Hyaluronidase 1 and $\beta$-hexosaminidase have redundant functions in hyaluronan and chondroitin sulfate degradation. J. Biol. Chem. 287, 16689-16697. doi: 10.1074/jbc.m112.350447

Habuchi, O. (2000). Diversity and functions of glycosaminoglycan sulfotransferases. Biochim. Biophys. Acta 1474, 115-127. doi: 10.1016/ s0304-4165(00)00016-7

Hamai, A., Hashimoto, N., Mochizuki, H., Kato, F., Makiguchi, Y., Horie, K., et al. (1997). Two distinct chondroitin sulfate ABC lyases an endoeliminase yielding tetrasaccharides and an exoeliminase preferentially acting on oligosaccharides. J. Biol. Chem. 272, 9123-9130. doi: 10.1074/jbc.272.14.9123

Han, W., Wang, W., Zhao, M., Sugahara, K., and Li, F. (2014). A Novel eliminase from a marine bacterium that degrades hyaluronan and chondroitin sulfate. J. Biol. Chem. 289, 27886-27898. doi: 10.1074/jbc.m114.590752

Handel, T. M., Johnson, Z., Crown, S. E., Lau, E. K., Sweeney, M., and Proudfoot, A. E. (2005). Regulation of protein function by glycosaminoglycans - as 
exemplified by chemokines. Annu. Rev. Biochem. 74, 385-410. doi: 10.1146/ annurev.biochem.72.121801.161747

Harmatz, P., and Shediac, R. (2017). Mucopolysaccharidosis VI: pathophysiology, diagnosis and treatment. Front Biosci. 22:385-406. doi: 10.2741/4490

Hayes, A. J., Smith, S. M., Caterson, B., and Melrose, J. (2018). Concise review: Stem/progenitor cell proteoglycans decorated with 7-D-4, 4-C-3, and 3-B-3(-) chondroitin sulfate motifs are morphogenetic markers of tissue development. Stem Cells 36, 1475-1486. doi: 10.1002/stem.2860

Henrissat, B. (1991). A classification of glycosyl hydrolases based on amino acid sequence similarities. Biochem. J. 280, 309-316. doi: 10.1042/bj2800309

Hiraoka, N., Nakagawa, H., Ong, E., Akama, T. O., Fukuda, M. N., and Fukuda, M. (2000). Molecular cloning and expression of two distinct human chondroitin 4-O-sulfotransferases that belong to the HNK-1 sulfotransferase gene family. J. Biol. Chem. 275, 20188-20196. doi: 10.1074/jbc.m002443200

Hirsch, R. J., Brody, H. J., and Carruthers, J. D. (2007). Hyaluronidase in the office: a necessity for every dermasurgeon that injects hyaluronic acid. J. Cosmet. Laser. Ther. 9, 182-1855. doi: 10.1080/14764170701291674

Hiyama, K., and Okada, S. (1975). Amino acid composition and physiochemical characterization of chondroitinase from Arthrobacter aurescens. J. Biochem. 78, 1183-1190. doi: 10.1093/oxfordjournals.jbchem.a131015

Hoffman, P., Meyer, K., and Linker, A. (1956). Transglycosylation during the mixed digestion of hyaluronic acid and chondroitin sulfate by testicular hyaluronidase. J. Biol. Chem. 219, 653-663.

Honda, T., Kaneiwa, T., Mizumoto, S., Sugahara, K., and Yamada, S. (2012). Hyaluronidases have strong hydrolytic activity toward chondroitin 4-sulfate comparable to that for hyaluronan. Biomolecules 2, 549-563. doi: 10.3390/ biom 2040549

Hoogendoorn, R. J., Wuisman, P. I., Smit, T. H., Everts, V. E., and Helder, M. N. (2007). Experimental intervertebral disc degeneration induced by chondroitinase ABC in the goat. Spine 32, 1816-1825. doi: 10.1097/brs. 0b013e31811ebac5

Howell, M. D., Bailey, L. A., Cozart, M. A., Gannon, B. M., and Gottschall, P. E. (2015). Hippocampal administration of chondroitinase ABC increases plaque-adjacent synaptic marker and diminishes amyloid burden in aged APPswe/PS1dE9 mice. Acta Neuropathol. Commun. 3:54.

Hsiao, J. C., Chung, C. S., and Chang, W. (1999). Vaccinia virus envelope D8L protein binds to cell surface chondroitin sulfate and mediates the adsorption of intracellular mature virions to cells. J. Virol. 73, 8750-8761. doi: 10.1128/jvi. 73.10.8750-8761.1999

Hwang, H. Y., Olson, S. K., Esko, J. D., and Horvitz, H. R. (2003). Caenorhabditis elegans early embryogenesis and vulval morphogenesis require chondroitin biosynthesis. Nature 423, 439-443. doi: 10.1038/nature01634

Iozzo, R. V., and Sanderson, R. D. (2011). Proteoglycans in cancer biology, tumour microenvironment and angiogenesis. J. Cell. Mol. Med. 15, 1013-1031. doi: 10.1111/j.1582-4934.2010.01236.x

Izumikawa, T., Kanagawa, N., Watamoto, Y., Okada, M., Saeki, M., Sakano, M., et al. (2010). Impairment of embryonic cell division and glycosaminoglycan biosynthesis in glucuronyltransferase-I-deficient Mice. J. Biol. Chem. 285, 12190-12196. doi: 10.1074/jbc.m110.100941

Izumikawa, T., Kitagawa, H., Mizuguchi, S., Nomura, K. H., Nomura, K., Tamura, J., et al. (2004). Nematode chondroitin polymerizing factor showing cell-/organspecific expression is indispensable for chondroitin synthesis and embryonic cell division. J. Biol. Chem. 279, 53755-53761. doi: 10.1074/jbc.m409615200

Jaime-Ramirez, A. C., Dmitrieva, N., Yoo, J. Y., Banasavadi-Siddegowda, Y., Zhang, J., Relation, T., et al. (2017). Humanized chondroitinase ABC sensitizes glioblastoma cells to temozolomide. J. Gene Med. 19:e2942. doi: 10.1002/jgm. 2942

Janzadeh, A., Sarveazad, A., Yousefifard, M., Dameni, S., Samani, F. S., Mokhtarian, K., et al. (2017). Combine effect of chondroitinase ABC and low level laser $(660 \mathrm{~nm})$ on spinal cord injury model in adult male rats. Neuropeptides 65 , 90-99. doi: 10.1016/j.npep.2017.06.002

Jedrzejas, M. J., and Stern, R. (2005). Structures of vertebrate hyaluronidases and their unique enzymatic mechanism of hydrolysis. Proteins 61, 227-238. doi: $10.1002 /$ prot. 20592

Kale, V., Friðjónsson, Ó, Jónsson, J. Ó, Kristinsson, H. G., Ómarsdóttir, S., and Hreggviðsson, G. Ó (2015). Chondroitin lyase from a marine Arthrobacter sp. MAT3885 for the production of chondroitin sulfate disaccharides. Mar. Biotechnol. 17, 479-492. doi: 10.1007/s10126-015-9629-9
Kaneiwa, T., Mizumoto, S., Sugahara, K., and Yamada, S. (2010). Identification of human hyaluronidase-4 as a novel chondroitin sulfate hydrolase that preferentially cleaves the galactosaminidic linkage in the trisulfated tetrasaccharide sequence. Glycobiology 20, 300-309. doi: $10.1093 /$ glycob/cwp174

Kang, H. G., Evers, M. R., Xia, G., Baenziger, J. U., and Schachner, M. (2002). Molecular cloning and characterization of chondroitin-4-O-sulfotransferase-3. A novel member of the HNK-1 family of sulfotransferases. J. Biol. Chem. 277, 34766-34772. doi: 10.1074/jbc.m204907200

Kastana, P., Choleva, E., Poimenidi, E., Karamanos, N., Sugahara, K., and Papadimitriou, E. (2019). Insight into the role of chondroitin sulfate $\mathrm{E}$ in angiogenesis. FEBS J. 286, 2921-2936. doi: 10.1111/febs.14830

Kato, D., Era, S., Watanabe, I., Arihara, M., Sugiura, N., Kimata, K., et al. (2010). Antiviral activity of chondroitin sulphate E targeting dengue virus envelope protein. Antiviral. Res. 88, 236-243. doi: 10.1016/j.antiviral.2010.09.002

Kauhausen, J. A., Thompson, L. H., and Parish, C. L. (2015). Chondroitinase improves midbrain pathway reconstruction by transplanted dopamine progenitors in Parkinsonian mice. Mol. Cell. Neurosci. 69, 22-29. doi: 10.1016/ j.mcn.2015.10.002

Kawahara, R., Granato, D. C., Carnielli, C. M., Cervigne, N. K., Oliveria, C. E., Martinez, C. A. R., et al. (2014). Agrin and perlecan mediate tumorigenic processes in oral squamous cell carcinoma. PLoS One 9:e115004. doi: 10.1371/ journal.pone.0115004

Khan, S. A., Peracha, H., Ballhausen, D., Wiesbauer, A., Rohrbach, M., Gautschi, M., et al. (2017). Epidemiology of mucopolysaccharidoses. Mol. Genet. Metab. 121, 227-240.

Kim, S. Y., Zhao, J., Liu, X., Fraser, K., Lin, L., Zhang, X., et al. (2017). Interaction of zika virus envelope protein with glycosaminoglycans. Biochemistry 56, 11511162. doi: 10.1021/acs.biochem.6b01056

Kinoshita, A., and Sugahara, K. (1999). Microanalysis of glycosaminoglycanderived oligosaccharides labeled with a fluorophore 2-aminobenzamide by high-performance liquid chromatography: application to disaccharide composition analysis and exosequencing of oligosaccharides. Anal. Biochem. 269, 367-378. doi: 10.1006/abio.1999.4027

Kinoshita, A., Yamada, S., Haslam, S. M., Morris, H. R., Dell, A., and Sugahara, K. (2001). Isolation and structural determination of novel sulfated hexasaccharides from squid cartilage chondroitin sulfate $\mathrm{E}$ that exhibits neuroregulatory activities. Biochemistry 40, 12654-12665. doi: 10.1021/bi015577n

Kitagawa, H., Tone, Y., Tamura, J., Neumann, K. W., Ogawa, T., Oka, S., et al. (1998). Molecular cloning and expression of glucuronyltransferase I involved in the biosynthesis of the glycosaminoglycan-protein linkage region of proteoglycans. J. Biol. Chem. 273, 6615-6618. doi: 10.1074/jbc.273.12. 6615

Klüppel, M., Wight, T. N., Chan, C., Hinek, A., and Wrana, J. L. (2005). Maintenance of chondroitin sulfation balance by chondroitin-4sulfotransferase 1 is required for chondrocyte development and growth factor signaling during cartilage morphogenesis. Development 132, 3989-4003. doi: $10.1242 /$ dev.01948

Kobayashi, M., Sugumaran, G., Liu, J. A., Shworak, N. W., Silbert, J. E., and Rosenberg, R. D. (1999). Molecular cloning and characterization of a human uronyl 2-sulfotransferase that sulfates iduronyl and glucuronyl residues in dermatan chondroitin sulfate. J. Biol. Chem. 274, 10474-10480. doi: 10.1074/ jbc.274.15.10474

Kobayashi, S., Fujikawa, S., and Ohmae, M. (2003). Enzymatic synthesis of chondroitin and its derivatives catalyzed by hyaluronidase. J. Am. Chem. Soc. 125, 14357-14369. doi: 10.1021/ja036584x

Kreil, G. (1995). Hyaluronidases-a group of neglected enzymes. Protein Sci. 4, 1666-1669. doi: 10.1002/pro.5560040902

Kurata, A., Matsumoto, M., Kobayashi, T., Deguchi, S., and Kishimoto, N. (2015). Hyaluronate lyase of a deep-sea Bacillus niacini. Mar. Biotechnol. 17, 277-284. doi: $10.1007 / \mathrm{s} 10126-015-9618-\mathrm{z}$

Kusche-Gullberg, M., and Kjellen, L. (2003). Sulfotransferases in glycosaminoglycan biosynthesis. Curr. Opin. Struct. Biol. 13, 605-611. doi: 10.1016/j.sbi.2003.08.002

Lemons, M. L., Howland, D. R., and Anderson, D. K. (1999). Chondroitin sulfate proteoglycan immunoreactivity increases following spinal cord injury and transplantation. Exp. Neuro. 160, 51-65. doi: 10.1006/exnr.1999. 7184 
Li, F., Nandini, C. D., Hattori, T., Bao, X., Murayama, D., Nakamura, T., et al. (2010). Structure of pleiotrophin- and hepatocyte growth factorbinding sulfated hexasaccharide determined by biochemical and computational approaches. J. Biol. Chem. 285, 27673-27685. doi: 10.1074/jbc.m110.118703

Li, F., Shetty, A. K., and Sugahara, K. (2007). Neuritogenic activity of chondroitin/dermatan sulfate hybrid chains of embryonic pig brain and their mimicry from shark liver. Involvement of the pleiotrophin and hepatocyte growth factor signaling pathways. J. Biol. Chem. 282, 2956-2966. doi: 10.1074/ jbc.m609296200

Li, F., ten Dam, G. B., Murugan, S., Yamada, S., Hashiguchi, T., Mizumoto, S., et al. (2008). Involvement of highly sulfated chondroitin sulfate in the metastasis of the lewis lung carcinoma cells. J. Biol. Chem. 283, 34294-34304. doi: 10.1074/ jbc.m806015200

Li, H. P., Komuta, Y., Kimura-Kuroda, J., van Kuppevelt, T. H., and Kawano, H. (2013). Roles of chondroitin sulfate and dermatan sulfate in the formation of a lesion scar and axonal regeneration after traumatic injury of the mouse brain. J. Neurotraum. 30, 413-425. doi: 10.1089/neu.2012.2513

Li, J., Sparkenbaugh, E. M., Su, G., Zhang, F., Xu, Y., Xia, K., et al. (2020). Enzymatic synthesis of chondroitin sulfate e to attenuate bacteria lipopolysaccharideinduced organ damage. ACS Cent. Sci. 6, 1199-1207. doi: 10.1021/acscentsci. $0 \mathrm{c} 00712$

Li, J., Su, G., and Liu, J. (2017). Enzymatic synthesis of homogeneous chondroitin sulfate oligosaccharides. Angew. Chem. Int. Ed. Engl. 56, 11784-11787. doi: 10.1002/anie.201705638

Lim, C. T., and Horwitz, A. L. (1981). Purification and properties of human Nacetylgalactosamine-6-sulfate sulfatase. Biochim. Biophys. Acta 657, 344-355. doi: 10.1016/0005-2744(81)90320-x

Lim, T. W., Leder, I. G., Bach, G., and Neufeld, E. F. (1974). An assay for iduronate sulfatase (Hunter corrective factor). Carbohydr. Res. 37, 103-109. doi: 10.1016/ s0008-6215(00)87067-6

Linhardt, R. J., Avci, F. Y., Toida, T., Kim, Y. S., and Cygler, M. (2006). CS lyases: structure, activity, and applications in analysis and the treatment of diseases. Adv. Pharmacol. 53, 187-215. doi: 10.1016/s1054-3589(05)53009-6

Link, J. M., Hu, J. C., and Athanasiou, K. A. (2020). Chondroitinase ABC enhances integration of self-assembled articular cartilage, but its dosage needs to be moderated based on neocartilage maturity. Cartilage [Epub ahead of print] doi: $10.1177 / 1947603520918653$

Lokeshwar, V. B., Rubinowicz, D., Schroeder, G. L., Forgacs, E., Minna, J. D., Block, N. L., et al. (2001). Stromal and epithelial expression of tumor markers hyaluronic acid and HYAL1 hyaluronidase in prostate cancer. J. Biol. Chem. 276, 11922-11932. doi: 10.1074/jbc.m008432200

Lü, D. S., Shono, Y., Oda, I., Abumi, K., and Kaneda, K. (1997). Effects of chondroitinase $\mathrm{ABC}$ and chymopapain on spinal motion segment biomechanics. An in vivo biomechanical, radiologic, and histologic canine study. Spine 22, 1828-1835. doi: 10.1097/00007632-199708150-00006

Lunin, V. V., Li, Y., Linhardt, R. J., Miyazono, H., Kyogashima, M., Kaneko, T., et al. (2004). High-resolution crystal structure of Arthrobacter aurescens chondroitin AC lyase: an enzyme-substrate complex defines the catalytic mechanism. J. Mol. Biol. 337, 367-386. doi: 10.1016/j.jmb.2003.12.071

Ly, M., Leach, F. E. I. I. I., Laremore, T. N., Toida, T., Amster, I. J., and Linhardt, R. J. (2011). The proteoglycan bikunin has a defined sequence. Nat. Chem. Biol. 7, 827-833. doi: $10.1038 /$ nchembio.673

Maccarana, M., Olander, B., Malmstrom, J., Tiedemann, K., Aebersold, R., Lindahl, U., et al. (2006). Biosynthesis of dermatan sulfate: chondroitin-glucuronate C5-epimerase is identical to SART2. J. Biol. Chem. 281, 11560-11568. doi: 10.1074/jbc.m513373200

Matalon, R., Arbogast, B., Justice, P., Brandt, I. K., and Dorfman, A. (1974). Morquio's syndrome: deficiency of a chondroitin sulfate $\mathrm{N}$-acetylhexosamine sulfate sulfatase. Biochem. Biophys. Res. Commun. 61, 759-765. doi: 10.1016/ 0006-291x(74)91022-5

Mathews, M. B. (1958). Isomeric chondroitin sulphates. Nature 181, 421-422. doi: $10.1038 / 181421 \mathrm{a} 0$

Michelacci, Y. M., and Dietrich, C. P. (1976). Chondroitinase C from Flavobacterium heparinum. J. Biol. Chem. 251, 1154-1158.

Mikami, T., Mizumoto, S., Kago, N., Kitagawa, H., and Sugahara, K. (2003). Specificities of three distinct human chondroitin/dermatan $\mathrm{N}$-acetylgalactosamine 4-O-sulfotransferases demonstrated using partially desulfated dermatan sulfate as an acceptor: implication of differential roles in dermatan sulfate biosynthesis. J. Biol. Chem. 278, 36115-36127. doi: 10.1074/jbc.m306044200

Mikami, T., Yasunaga, D., and Kitagawa, H. (2009). Contactin-1 is a functional receptor for neuroregulatory chondroitin sulfate-E. J. Biol. Chem. 284, 44944499. doi: 10.1074/jbc.m809227200

Miyachi, K., Wakao, M., and Suda, Y. (2015). Syntheses of chondroitin sulfate tetrasaccharide structures containing 4,6-disulfate patterns and analysis of their interaction with glycosaminoglycan-binding protein. Bioorg. Med. Chem. Lett. 25, 1552-1555. doi: 10.1016/j.bmcl.2015.02.011

Miyazono, H., Kikuchi, H., Yoshida, K., Morikawa, K., and Tokuyasu, K. (1990). Purification and properties of three novel chondroitinases. Glycoconj. J. 8, 201.

Mizuguchi, S., Uyama, T., Kitagawa, H., Nomura, K. H., Dejima, K., Gengyo-Ando, K., et al. (2003). Chondroitin proteoglycans are involved in cell division of Caenorhabditis elegans. Nature 423, 443-448. doi: 10.1038/nature01635

Mizumoto, S., Murakoshi, S., Kalayanamitra, K., Deepa, S. S., Fukui, S., Kongtawelert, P., et al. (2013a). Highly sulfated hexasaccharide sequences isolated from chondroitin sulfate of shark fin cartilage: insights into the sugar sequences with bioactivities. Glycobiology 23, 155-168. doi: 10.1093/glycob/ cws 137

Mizumoto, S., Watanabe, M., Yamada, S., and Sugahara, K. (2013b). Expression of $\mathrm{N}$-acetylgalactosamine 4-sulfate 6-O-sulfotransferase involved in chondroitin sulfate synthesis is responsible for pulmonary metastasis. Biomed. Res. Int. 2013:656319.

Mizumoto, S., and Sugahara, K. (2013). Glycosaminoglycans are functional ligands for receptor for advanced glycation end-products in tumors. FEBS J. 280, 2462-2470. doi: 10.1111/febs.12156

Mizumoto, S., Takahashi, J., and Sugahara, K. (2012). Receptor for advanced glycation end products (RAGE) functions as a receptor for specific sulfated glycosaminoglycans, and anti-RAGE antibody or the sulfated glycosaminoglycans delivered in vivo inhibit pulmonary metastasis of tumor cells. J. Biol. Chem. 287, 18985-18994. doi: 10.1074/jbc.m111.313437

Mondello, S. E., Jefferson, S. C., Tester, N. J., and Howland, D. R. (2015). Impact of treatment duration and lesion size on effectiveness of chondroitinase treatment post-SCI. Exp. Neuro. 267, 64-77. doi: 10.1016/j.expneurol.2015.02.028

Moon, L. D., Asher, R. A., Rhodes, K. E., and Fawcett, J. W. (2001). Regeneration of CNS axons back to their target following treatment of adult rat brain with chondroitinase ABC. Nat. Neurosci. 4, 465-466. doi: 10.1038/87415

Mullen, C. A., Thompson, J. N., Richard, L. A., and Chan, K. W. (2000). Unrelated umbilical cord blood transplantation in infancy for mucopolysaccharidosis type IIB (Hunter syndrome) complicated by autoimmune hemolytic anemia. Bone Marrow Transpl. 25, 1093-1097. doi: 10.1038/sj.bmt.1702397

Myette, J. R., Shriver, Z., Claycamp, C., McLean, M. W., Venkataraman, G., and Sasisekharan, R. (2003). The heparin/heparan sulfate 2-O-sulfatase from Flavobacterium heparinum - Molecular cloning, recombinant expression, and biochemical characterization. J. Biol. Chem. 278, 12157-12166. doi: 10.1074/ jbc.m 211420200

Nadanaka, S., and Sugahara, K. (1997). The unusual tetrasaccharide sequence GlcA beta 1-3GalNAc(4-sulfate) beta 1-4GlcA(2-sulfate) beta 1-3GalNAc(6-sulfate) found in the hexasaccharides prepared by testicular hyaluronidase digestion of shark cartilage chondroitin sulfate D. Glycobiology 7, 253-263. doi: 10.1093/ glycob/7.2.253

Namburi, R. B., Berteau, O., Spillmann, D., and Rossi, M. (2016). Chondroitinase AC: a host-associated genetic feature of Helicobacter bizzozeronii. Vet. Microbiol. 186, 21-27. doi: 10.1016/j.vetmic.2016.02.013

Nandi, S., Akhter, M. P., Seifert, M. F., Dai, X. M., and Stanley, E. R. (2006). Developmental and functional significance of the CSF-1 proteoglycan chondroitin sulfate chain. Blood 107, 786-795. doi: 10.1182/blood-2005-051822

Nandini, C. D., and Sugahara, K. (2006). Role of the sulfation pattern of chondroitin sulfate in its biological activities and in the binding of growth factors. Adv. Pharmacol. 53, 253-279. doi: 10.1016/s1054-3589(05)53012-6

Ndeh, D., Munoz, J. M., Cartmell, A., Bulmer, D., Wills, C., Henrissat, B., et al. (2018). The human gut microbe Bacteroides thetaiotaomicron encodes the founding member of a novel glycosaminoglycan-degrading polysaccharide lyase family PL29. J. Biol. Chem. 293, 17906-17916. doi: 10.1074/jbc.ra118. 004510

Ochiai, H., Fujikawa, S., and Ohmae, M. (2007a). Enzymatic copolymerization to hybrid glycosaminoglycans: a novel strategy for intramolecular hybridization 
of polysaccharides. Biomacromolecules 8, 1802-1806. doi: 10.1021/ bm0700340

Ochiai, H., Ohmae, M., Mori, T., and Kobayashi, S. (2007b). Hyaluronidasecatalyzed copolymerization for the single-step synthesis of functionalized hyaluronan derivatives. Biomacromolecules 8, 1327-1332. doi: 10.1021/ bm061136d

Ohtake, S., Ito, Y., Fukuta, M., and Habuchi, O. (2001). Human $\mathrm{N}$-acetylgalactosamine 4-sulfate 6-O-sulfotransferase cDNA is related to human B cell recombination activating gene-associated gene. J. Biol. Chem. 276, 43894-43900. doi: 10.1074/jbc.m104922200

Ohya, T., and Kaneko, Y. (1970). Novel hyaluronidase from streptomyces. Biochim. Biophys. Acta. 198, 607-609. doi: 10.1016/0005-2744(70)90139-7

Okajima, T., Yoshida, K., Kondo, T., and Furukawa, K. (1999). Human homolog of Caenorhabditis elegans sqv-3 gene is galactosyltransferase I involved in the biosynthesis of the glycosaminoglycan-protein linkage region of proteoglycans. J. Biol. Chem. 274, 22915-22918. doi: 10.1074/jbc.274.33.22915

Pacheco, B., Malmstrom, A., and Maccarana, M. (2009). Two dermatan sulfate epimerases form iduronic acid domains in dermatan sulfate. J. Biol. Chem. 284, 9788-9795. doi: 10.1074/jbc.m809339200

Parenti, G., Meroni, G., and Ballabio, A. (1997). The sulfatase gene family. Curr. Opin. Genet. Dev. 7, 386-391. doi: 10.1016/s0959-437x(97)80153-0

Pearson, C. S., Mencio, C. P., Barber, A. C., Martin, K. R., and Geller, H. M. (2018). Identification of a critical sulfation in chondroitin that inhibits axonal regeneration. eLife 7:e37139.

Peng, C., Wang, Q., Wang, S., Wang, W., Jiao, R., Han, W., et al. (2018). A chondroitin sulfate and hyaluronic acid lyase with poor activity to glucuronyl 4,6-O-disulfated N-acetylgalactosamine (E-type)-containing structures. J. Biol. Chem. 293, 4230-4243. doi: 10.1074/jbc.ra117.001238

Ponder, K. P., and Haskins, M. E. (2007). Gene therapy for mucopolysaccharidosis. Expert Opin. Biol. Ther. 7, 1333-1345.

Pudelko, A., Wisowski, G., Olczyk, K., and Kozma, E. M. (2019). The dual role of the glycosaminoglycan chondroitin-6-sulfate in the development, progression and metastasis of cancer. FEBS J. 286, 1815-1837. doi: 10.1111/febs.14748

Purushothaman, A., Fukuda, J., Mizumoto, S., ten Dam, G. B., van Kuppevelt, T. H., Kitagawa, H., et al. (2007). Functions of chondroitin sulfate/dermatan sulfate chains in brain development. critical roles of $\mathrm{E}$ and $\mathrm{iE}$ disaccharide units recognized by a single chain antibody GD3G7. J. Biol. Chem. 282, 19442-19452. doi: $10.1074 /$ jbc.m700630200

Rai, S. K., Duh, F. M., Vigdorovich, V., Danilkovitch-Miagkova, A., Lerman, M. I., and Millet, A. D. (2001). Candidate tumor suppressor HYAL2 is a glycosylphosphatidylinositol (GPI)-anchored cell-surface receptor for jaagsiekte sheep retrovirus, the envelope protein of which mediates oncogenic transformation. Proc. Natl. Acad. Sci. U.S.A. 98, 4443-4448. doi: 10.1073/pnas. 071572898

Raman, R., Sasisekharan, V., and Sasisekharan, R. (2005). Structural insights into biological roles of protein-glycosaminoglycan interactions. Chem. Biol. 12, 267-277. doi: 10.1016/j.chembiol.2004.11.020

Sabeur, K., Cherr, G. N., Yudin, A. I., Primakoff, P., Li, M. W., and Overstreet, J. W. (1997). The PH-20 protein in human spermatozoa. J. Androl. 8, 151-158.

Sarveazad, A., Babahajian, A., Bakhtiari, M., Soleimani, M., Behnam, B., Yari, A., et al. (2017). The combined application of human adipose derived stem cells and Chondroitinase $\mathrm{ABC}$ in treatment of a spinal cord injury model. Neuropeptides 61, 39-47. doi: 10.1016/j.npep.2016.07.004

Sarvela, P. J., Paloheimo, M. P., and Nikki, P. H. (1994). Comparison of pHadjusted bupivacaine $0.75 \%$ and a mixture of bupivacaine $0.75 \%$ and lidocaine $2 \%$, both with hyaluronidase, in day-case cataract surgery under regional anesthesia. Anesth. Analg. 9, 35-39.

Sawamoto, K., Álvarez González, J. V., Piechnik, M., Otero, F. J., Couce, M. L., Suzuki, Y., et al. (2020). Mucopolysaccharidosis IVA: diagnosis, treatment, and management. Int. J. Mol. Sci. 21:1517. doi: 10.3390/ijms21041517

Sawamoto, K., Chen, H. H., Alméciga-Díaz, C. J., Mason, R. W., and Tomatsu, S. (2018). Gene therapy for Mucopolysaccharidoses. Mol. Genet. Metab. 123, 59-68. doi: 10.1016/j.ymgme.2017.12.434

Schwartz, N. B., and Domowicz, M. S. (2018). Proteoglycans in brain development and pathogenesis. FEBS Lett. 592, 3791-3805. doi: 10.1002/1873-3468.13026

Shaklee, P. N., Glaser, J. H., and Conrad, H. E. (1985). A sulfatase specific for glucuronic acid 2-sulfate residues in glycosaminoglycans. J. Biol. Chem. 260, 9146-9149.
Shida, M., Mikami, T., Tamura, J. I., and Kitagawa, H. (2019). Chondroitin sulfate$\mathrm{D}$ promotes neurite outgrowth by acting as an extracellular ligand for neuronal integrin $\alpha$ V 33 . Biochim. Biophys. Acta Gen. Subj. 1863, 1319-1331. doi: 10. 1016/j.bbagen.2019.06.004

Shioiri, T., Tsuchimoto, J., Watanabe, H., and Sugiura, N. (2016). Sequence determination of synthesized chondroitin sulfate dodecasaccharides. Glycobiology 26, 592-606. doi: 10.1093/glycob/cww008

Silbert, J. E., and Sugumaran, G. (2002). Biosynthesis of chondroitin/dermatan sulfate. IUBMB Life 54, 177-186.

Singh, J., Di Ferrante, N., Niebes, P., and Tavella, D. (1976). N-acetylgalactosamine6-sulfate sulfatase in man. Absence of the enzyme in Morquio disease. J. Clin. Invest. 57, 1036-1040. doi: 10.1172/jci108345

Stern, R. (2003). Devising a pathway for hyaluronan catabolism: are we there yet? Glycobiology 13, 105R-115R.

Stern, R. (2004). Hyaluronan catabolism: a new metabolic pathway. Eur. J. Cell Biol. 83, 317-325. doi: 10.1078/0171-9335-00392

Stern, R., and Jedrzejas, M. J. (2006). Hyaluronidases: their genomics, structures, and mechanisms of action. Chem. Rev. 106, 818-839. doi: 10.1021/cr050247k

Sting, R., Schaufuss, P., and Blobel, H. (1990). Isolation and characterization of hyaluronidases from Streptococcus dysgalactiae, S. zooepidemicus and S. equi. Zentralbl. Bakteriology 272, 276-282. doi: 10.1016/s0934-8840(11)80028-9

Sugahara, K., and Kitagawa, H. (2000). Recent advances in the study of the biosynthesis and functions of sulfated glycosaminoglycans. Curr. Opin. Struct. Biol. 10, 518-527. doi: 10.1016/s0959-440x(00)00125-1

Sugahara, K., and Kojima, T. (1996). Specificity studies of bacterial sulfatases by means of structurally defined sulfated oligosaccharides isolated from shark cartilage chondroitin sulfate D. Eur. J. Biochem. 239, 865-870. doi: 10.1111/ j.1432-1033.1996.0865u.x

Sugahara, K., and Mikami, T. (2007). Chondroitin/dermatan sulfate in the central nervous system. Curr. Opin. Struct. Biol. 17, 536-545. doi: 10.1016/j.sbi.2007. 08.015

Sugahara, K., Mikami, T., Uyama, T., Mizuguchi, S., Nomura, K., and Kitagawa, H. (2003). Recent advances in the structural biology of chondroitin sulfate and dermatan sulfate. Curr. Opin. Struct. Biol. 13, 612-620. doi: 10.1016/j.sbi.2003. 09.011

Sugimura, T., Kato, F., Mimatsu, K., Takenaka, O., and Iwata, H. (1996). Experimental chemonucleolysis with chondroitinase ABC in monkeys. Spine 21, 161-165. doi: 10.1097/00007632-199601150-00001

Sugiura, N., Ikeda, M., Shioiri, T., Yoshimura, M., Kobayashi, M., and Watanabe, H. (2013). Chondroitinase from baculovirus Bombyx mori nucleopolyhedrovirus and chondroitin sulfate from silkworm Bombyx mori. Glycobiology 23, 1520-1530. doi: 10.1093/glycob/cwt082

Sugiura, N., Setoyama, Y., Chiba, M., Kimata, K., and Watanabe, H. (2011). Baculovirus envelope protein odv-e66 is A novel chondroitinase with distinct substrate specificity. J. Biol. Chem. 286, 29026-29034. doi: 10.1074/jbc.m111. 251157

Sullivan, W. J., Mullen, P. J., Schmid, E. W., Flores, A. A., Momcilovic, M., Sharpley, M. S., et al. (2018). Extracellular matrix remodeling regulates glucose metabolism through TXNIP destabilization. Cell 175, 117-132. doi: 10.1016/j. cell.2018.08.017

Takeuchi, J. (1972). Effect of chondroitinases on the growth of solid Ehrlich ascites tumour. Br. J. Cancer Suppl. 26, 115-119. doi: 10.1038/bjc.1972.17

Taylor, K. R., and Gallo, R. L. (2006). Glycosaminoglycans and their proteoglycans: host-associated molecular patterns for initiation and modulation of inflammation. FASEB J. 20, 9-22. doi: 10.1096/fj.05-4682rev

Theocharis, A. D., Skandalis, S. S., Tzanakakis, G. N., and Karamanos, N. K. (2010). Proteoglycans in health and disease: novel roles for proteoglycans in malignancy and their pharmacological targeting. FEBS J. 277, 3904-3923. doi: $10.1111 / j .1742-4658.2010 .07800 . x$

Thompson, J. N., Stoolmiller, A. C., Matalon, R., and Dorfman, A. (1973). $\mathrm{N}$-Acetyl- $\beta$-hexosaminidase: role in the degradation of glycosaminoglycans. Science 181, 866-867. doi: 10.1126/science.181.4102.866

Tomatsu, S., Fukuda, S., Masue, M., Sukegawa, K., Fukao, T., Yamagishi, A., et al. (1991). Morquio disease: isolation, characterization and expression of fulllength cDNA for human N-acetylgalactosamine-6-sulfate sulfatase. Biochem. Biophys. Res. Commun. 181, 677-683. doi: 10.1016/0006-291x(91)91244-7

Tribble, J. R., Williams, P. A., Caterson, B., Sengpiel, F., and Morgan, J. E. (2018). Digestion of the glycosaminoglycan extracellular matrix by chondroitinase $\mathrm{ABC}$ 
supports retinal ganglion cell dendritic preservation in a rodent model of experimental glaucoma. Mol. Brain 11:69.

Trowbridge, J. M., and Gallo, R. L. (2002). Dermatan sulfate: new functions from an old glycosaminoglycan. Glycobiology 12, 117R-125R.

Trowbridge, J. M., Rudisill, J. A., Ron, D., and Gallo, R. L. (2002). Dermatan sulfate binds and potentiates activity of keratinocyte growth factor (FGF-7). J. Biol. Chem. 277, 42815-42820. doi: 10.1074/jbc.m204959200

Tully, S. E., Rawat, M., and Hsieh-Wilson, L. (2006). Discovery of a TNF$\alpha$ antagonist using chondroitin sulfate microarrays. J. Am. Chem. Soc. 128, 7740-7741. doi: 10.1021/ja061906t

Ueoka, C., Kaneda, N., Okazaki, I., Nadanaka, S., Muramatsu, T., and Sugahara, K. (2000). Neuronal cell adhesion, mediated by the heparin-binding neuroregulatory factor midkine, is specifically inhibited by chondroitin sulfate E. Structural ans functional implications of the over-sulfated chondroitin sulfate. J. Biol. Chem. 275, 37407-37413. doi: 10.1074/jbc.m002538200

Ulmer, J. E., Vilen, E. M., Namburi, R. B., Benjdia, A., Beneteau, J., Malleron, A., et al. (2014). Characterization of glycosaminoglycan (GAG) sulfatases from the human gut symbiont Bacteroides thetaiotaomicron reveals the first gagspecific bacterial endosulfatase. J. Biol. Chem. 289, 24289-24303. doi: 10.1074/ jbc.m114.573303

Valcarcel, J., Novoa-Carballal, R., Pérez-Martín, R. I., Reis, R. L., and Vázquez, J. A. (2017). Glycosaminoglycans from marine sources as therapeutic agents. Biotechnol. Adv. 35, 711-725. doi: 10.1016/j.biotechadv.2017.07.008

Volpi, N. (2007). Analytical aspects of pharmaceutical grade chondroitin sulfates. J. Pharm. Sci. 96, 3168-3180. doi: 10.1002/jps.20997

Volpi, N. (2009). Quality of different chondroitin sulfate preparations in relation to their therapeutic activity. J. Pharm. Pharmacol. 61, 1271-1280. doi: 10.1211/ jpp.61.10.0002

Wang, H., Katagiri, Y., McCann, T. E., Unsworth, E., Goldsmith, P., Yu, Z. X., et al. (2008). Chondroitin-4-sulfation negatively regulates axonal guidance and growth. J. Cell Sci. 121, 3083-3091. doi: 10.1242/jcs.032649

Wang, S., Guan, J., Zhang, Q., Chen, X., and Li, F. (2019a). Identification and signature sequences of bacterial delta $(4,5)$ hexuronate-2-O-sulfatases. Front. Microbiol. 10:704. doi: 10.3389/fmicb.2019.00704

Wang, S., Su, T., Zhang, Q., Guan, J., He, J., Gu, L., et al. (2019b). Comparative study of two chondroitin sulfate/dermatan sulfate 4-O-sulfatases with high identity. Front. Microbiol. 10:1309. doi: 10.3389/fmicb.2019.01309

Wang, W., Cai, X., Han, N., Han, W., Sugahara, K., and Li, F. (2017). Sequencing of chondroitin sulfate oligosaccharides using a novel exolyase from a marine bacterium that degrades hyaluronan and chondroitin sulfate/dermatan sulfate. Biochem. J. 474, 3831-3848. doi: 10.1042/bcj20170591

Wang, W., Han, W., Cai, X., Zheng, X., Sugahara, K., and Li, F. (2015). Cloning and characterization of a novel chondroitin sulfate/dermatan sulfate 4-Oendosulfatase from a marine bacterium. J. Biol. Chem. 290, 7823-7832. doi: 10.1074/jbc.m114.629154

Whiteman, D. A., and Kimura, A. (2017). Development of idursulfase therapy for mucopolysaccharidosis type II (Hunter syndrome): the past, the present and the future. Drug Des. Dev. Ther. 11, 2467-2480. doi: 10.2147/dddt.s139601
Wicker, G., Prill, V., Brooks, D., Gibson, G., Hopwood, J., von Figura, K., et al. (1991). Mucopolysaccharidosis VI (Maroteaux-Lamy syndrome). An intermediate clinical phenotype caused by substitution of valine for glycine at position 137 of arylsulfatase B. J. Biol. Chem. 266, 21386-21391.

Wilson, P. J., Morris, C. P., Anson, D. S., Occhiodoro, T., Bielicki, J., Clements, P. R., et al. (1990). Hunter syndrome: isolation of an iduronate-2-sulfatase cDNA clone and analysis of patient DNA. Proc. Natl. Acad. Sci. U.S.A. 87, 8531-8535. doi: 10.1073/pnas.87.21.8531

Wood, K. M., Wusteman, F. S., and Curtis, C. G. (1973). The degradation of intravenously injected chondroitin 4-sulfate in the rat. Biochem. J. 134, 10091013. doi: 10.1042/bj1341009

Yamada, S. (2015). Role of hyaluronidases in the catabolism of chondroitin sulfate. Adv. Exp. Med. Biol. 842, 185-197. doi: 10.1007/978-3-319-11280-0_12

Yamagata, T., Saito, H., Habuchi, O., and Suzuki, S. (1968). Purification and properties of bacterial chondroitinases and chondrosulfatases. J. Biol. Chem. 243, 1523-1535.

Yamaguchi, K., Tamaki, H., and Fukui, S. (2006). Detection of oligosaccharide ligands for hepatocyte growth factor/scatter factor (HGF/SF), keratinocyte growth factor (KGF/FGF-7), RANTES and heparin cofactor II by neoglycolipid microarrays of glycosaminoglycan-derived oligosaccharide fragments. Glycoconj. J. 23, 513-523. doi: 10.1007/s10719-006-7151-z

Yamauchi, S., Mita, S., Matsubara, T., Fukuta, M., Habuchi, H., Kimata, K., et al. (2000). Molecular cloning and expression of chondroitin 4-sulfotransferase. J. Biol. Chem. 275, 8975-8981. doi: 10.1074/jbc.275.12.8975

Yin, F.-X., Wang, F.-S., and Sheng, J.-Z. (2016). Uncovering the catalytic direction of chondroitin AC exolyase: from the reducing end towards the non-reducing end. J. Biol. Chem. 291, 4399-4406. doi: 10.1074/jbc.c115.708396

Yoo, M., Khaled, M., Gibbs, K. M., Kim, J., Kowalewski, B., Dierks, T., et al. (2013). Arylsulfatase B improves locomotor function after mouse spinal cord injury. PLoS ONE 8:e57415. doi: 10.1371/journal.pone.0057415

Zhang, X., Liu, H., Yao, W., Meng, X., and Li, Z. (2019). Semisynthesis of chondroitin sulfate oligosaccharides based on the enzymatic degradation of chondroitin. J. Org. Chem. 84, 7418-7425. doi: 10.1021/acs.joc.9b0 0112

Zhu, C., Zhang, J., Zhang, J., Jiang, Y., Shen, Z., Guan, H., et al. (2017). Purification and characterization of chondroitinase $\mathrm{ABC}$ from Acinetobacter sp C26. Int. J. Biol. Macromol. 95, 80-86. doi: 10.1016/j.ijbiomac.2016.10.044

Conflict of Interest: The authors declare that the research was conducted in the absence of any commercial or financial relationships that could be construed as a potential conflict of interest.

Copyright (c) 2020 Wang, Shi, Qin and Li. This is an open-access article distributed under the terms of the Creative Commons Attribution License (CC BY). The use, distribution or reproduction in other forums is permitted, provided the original author(s) and the copyright owner(s) are credited and that the original publication in this journal is cited, in accordance with accepted academic practice. No use, distribution or reproduction is permitted which does not comply with these terms. 